I

\title{
THERMIONIC REACTOR DESIGN STUDIES
}

\author{
Alfred Schock \\ Fairchild Space and Defense Corporation
}

20301 Century Blvd.

Germantown, MD 20874

June 1994 


\section{DISCLAIMER}

This report was prepared as an account of work sponsored by an agency of the United States Government. Neither the United States Government nor any agency Thereof, nor any of their employees, makes any warranty, express or implied, or assumes any legal liability or responsibility for the accuracy, completeness, or usefulness of any information, apparatus, product, or process disclosed, or represents that its use would not infringe privately owned rights. Reference herein to any specific commercial product, process, or service by trade name, trademark, manufacturer, or otherwise does not necessarily constitute or imply its endorsement, recommendation, or favoring by the United States Government or any agency thereof. The views and opinions of authors expressed herein do not necessarily state or reflect those of the United States Government or any agency thereof. 


\section{DISCLAIMER}

Portions of this document may be illegible in electronic image products. Images are produced from the best available original document. 


\title{
THERMIONIC REACTOR DESIGN STUDIES
}

\author{
Alfred Schock \\ Fairchild Space and Defense Corporation \\ 20301 Century Blvd. \\ Germantown, MD 20874
}

June 1994 


\title{
THERMIONIC REACTOR DESIGN STUDIES
}

\author{
Alfred Schock \\ Fairchild Space and Defense Corporation \\ Germantown, MD 20874
}

\section{Abstract and Introduction}

During the 1960 's and early 70 's the author performed extensive design studies, analyses, and tests aimed at thermionic reactor concepts that differed significantly from those pursued by other investigators. Those studies, like most others under Atomic Energy Commission (AEC and DOE) and the National Aeronautics and Space Administration (NASA) sponsorship, were terminated in the early 1970 's. Some of this work was previously published, but much of it was never made available in the open literature. U.S. interest in thermionic reactors resumed in the early 80 's, and was greatly intensified by reports about Soviet ground and flight tests in the late 80 's. This recent interest resulted in renewed U.S. thermionic reactor development programs, primarily under Department of Defense (DOD) and Department of Energy (DOE) sponsorship. Since most current investigators have not had an opportunity to study all of the author's previous work, a review of the highlights of that work may be of value to them.

The present paper describes some of the author's conceptual designs and their rationale, and the special analytical techniques developed to analyze their performance. The basic designs, first published in 1963, are based on single-cell converters, either double-ended diodes extending over the full height of the reactor core or singleended diodes extending over half the core height. In that respect they are similar to the thermionic fuel elements employed in the Topaz-2 reactor subsequently developed in the Soviet Union, copies of which were recently imported by the U.S. As in the Topaz-2 case, electrically heated steady-state performance tests of the converters are possible before fueling.

Where the author's concepts differed from the later Topaz-2 design was in the relative location of the emitter and the collector. Placing the fueled emitter on the outside of the cylindrical diodes permits much higher axial conductances to reduce ohmic losses in the electrodes of fullcore-height diodes. Moreover, placing the fuel on the outside of the diode makes possible reactors with much higher fuel volume fractions, which enable power-flattened fast reactors scalable to very low power levels without the need for life-limiting hydride moderators or the use of efficiency-limiting driver fuel.

In addition, with the fuel on the outside its swelling does not increase the emitter diameter or reduce the interelectrode gap. This should permit long lifetimes even with closer spacings, which can significantly improve the system efficiencies. This was confirmed by coupled neutronic, thermal, thermionic, and electrical system analyses - some of which are presented in this paper - and by subsequent experiments. A companion paper presented next describes the fabrication and testing of full-scale converter elements, both fueled and unfueled, and summarizes the test results obtained.

\section{DESIGN CONCEPT}

In a 1963 paper, Schock and Eisen ${ }^{1}$, proposed a thermionic reactor design concept paper encompassing the following features:

1. A cylindrical thermionic diode, externally heated by means of a coaxial hexagonal fuel element.

2. The diode to extend over the full height of the reactor core.

3. A ceramic layer between the inner coolant pipe and the collector.

4. A highly conductive copper layer cast in place between the insulated coolant pipe and the collector. 
5. Fuel distribution adjusted to achieve a uniform emitter temperature.

6. The insulator, conductor, and nuclear fuel all to be outside the cesium envelope.

During the subsequent decade, many variants of this design were investigated by the author, but the basic concept remained unchanged. The chief advantage of placing the emitter and fuel on the outside of the cylindrical diode is that their cross-sectional areas can be arbitrarily increased without increasing the converter's electrode area. A large cross-sectional area of the hightemperature (and high-resistivity) emitter reduces ohmic losses and voltage gradients, which are of critical importance in full-length diodes. Increasing the cross-sectional area of the fuel makes it possible to achieve a very high fuel volume fraction in the reactor core, which facilitates power flattening and makes possible compact critical, fast-reactor cores for low-power systems, avoiding the need for lifelimiting hydride moderators or efficiencylimiting driver fuel.

The same 1963 paper contained the following summary of the advantages offered by the full-length externally fueled diode concept:

1. The nuclear fuel is outside the cesium diode, and continuous fission product venting is possible.

2. Fuel growth does not affect the diodes' internal structure.

3. The difference between the maximum fuel temperature and the emitter temperature is only two-fifths as large as in previously proposed designs (for equal power densities).

4. The open-circuit temperature rise is only about one third the corresponding value of the internally fueled case.

5. A full-scale device can be developed, built, and tested by electrical heating, yielding an accurate simulation of the actual converter operation.
6. In final production, each externally fueled diode can be individually performance tested for quality, without resorting to inpile operation.

7. A large fraction of the reactor volume is occupied by the fuel, which favors the achievement of compact critical size. This makes the system adaptable to relatively lower power-levels.

8. The full-length diode is basically simple and reliable. Complex connecting members and axial voids between adjacent diodes are eliminated.

9. Casting of the conductive layer between insulator and collector facilitates fabrication and promotes good thermal contact.

10. As each cesium envelope contains only a single diode, stray emission between diodes is eliminated.

11. Since the ceramic insulator is not exposed to cesium vapor, outgassing is simplified and the danger of electrical breakdown through cracks in the ceramic is minimized.

12. The potentially uniform emitter temperature makes it possible to operate the entire diode near its optimum condition.

Subsequent experience would cause some change of emphasis among this list. But the basic list has stood the test of time quite well, and most of the listed advantages still hold true.

\section{REACTOR DESIGN}

Thermionic reactors based on externally fueled single-cell TFEs still permit considerable variation with respect to such items as fuel form and geometry, ratio of diode length to reactor core length, core layout and assembly sequence, electrical connectors and diode network, fission gas venting and diode cooling. Designs based on various of the above options have been described in previous reports. $2,3,4,5$ The present discussion 
will confine itself to describing one specific design concept excerpted from a 1970 report. $^{6}$ In addition to this description, the paper discusses some of the salient features of the design, with particular reference to its use in space, and presents typical sizes and weights for a wide range of power levels. The design described was selected not because it is necessarily the latest or best option, but because it was most thoroughly illustrated and documented.

\section{Fuel Element}

The studies described here are based on two alternative fuel element configurations, as illustrated in Figure 1. One of the alternatives utilizes a hexagonal "revolver" body, in which the central emitter hole is surrounded by six fuel chamber holes, loaded with bulk $\mathrm{UO}_{2}$ fuel. The other alternative examined is an annular cylindrical cermet fuel element. (Except where otherwise stated, all results are based on 93\%-enriched $\mathrm{U}^{235} \mathrm{O}_{2}$ fuel and natural tungsten metal, with not more than 60 volume-percent $\mathrm{UO}_{2}$ in the cermet.)
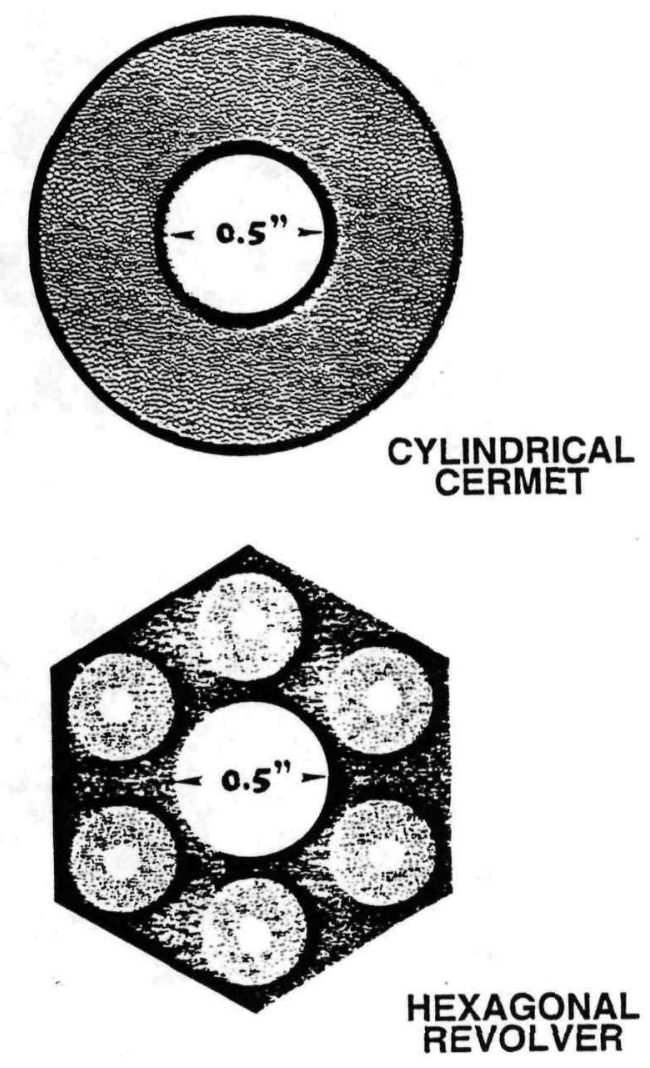

Fig.1 Fuel-Emitter Geometry
Figure 1 illustrates the unique features of the external-fuel diode: the fuel volume fraction can be increased without changing the emitter diameter. Uncoupling these two variables makes it practical to build a reactor core with a very high fuel volume fraction, which is of particular importance for achieving criticality in low-power thermionic reactors. With the external-fuel diode configuration described here it is quite practical to design an unmoderated driverless $\mathrm{U}^{235}$ fueled thermionic reactor producing $50 \mathrm{~kW}$ or less.

The high fuel volume fraction made possible by the external-fuel design is of importance not only for low power reactors but also at higher power levels, since it affords the designer much greater latitude in solving some of his other problems. For example, one of the principal problems in thermionic reactor development is maintaining the dimensional stability and leak tightness of the fuel-emitter assembly and avoiding interelectrode shorts during long-term high-temperature operation, in spite of fuel swelling caused by fission product buildup. Two promising methods for relieving this problem are increasing the void fraction, particularly in the case of cermet fuels, and increasing the ratio of metal wall thickness to fuel pin diameter in the case of bulk fuel, such as $\mathrm{UO}_{2}$. Since both of these methods reduce the uranium concentration in the reactor, they can only be employed if a compensating increase in the fuel chamber volume fraction can be made to maintain criticality.

\section{Collector Cooling and Converter Modularity}

Turning our attention to the diode collectors, each has a central, cylindrical coolant hole, which lends itself to either liquid metal or heatpipe cooling. For the latter case, it should be emphasized that the heatpipe postulated here is a relatively low temperature device, to transfer reject heat from the diode collectors to liquid metal-cooled heat exchangers. At these temperatures, alkali metal heatpipes have successfully operated for many thousands of hours. The design does not assume the use of high temperature heatpipes to transfer heat between fuel and emitter.

Of the two cooling options, heatpipe cooling was assumed in the present studies, because this 
permits some very unusual and - we believe desirable design features that would not be possible if liquid metal cooling were employed. Chief among these is converter modularity and replaceability.

Figure 2 illustrates the thermionic fuel module, or TFM, which is the basic building block of the reactor design presented here. Each TFM consists of nuclear fuel to generate the thermal power, a thermionic diode to convert it to electrical power, a heatpipe to deliver the rejected heat to the liquid metal coolant, and a cesium reservoir to provide the vapor pressure needed for an efficient conversion process.

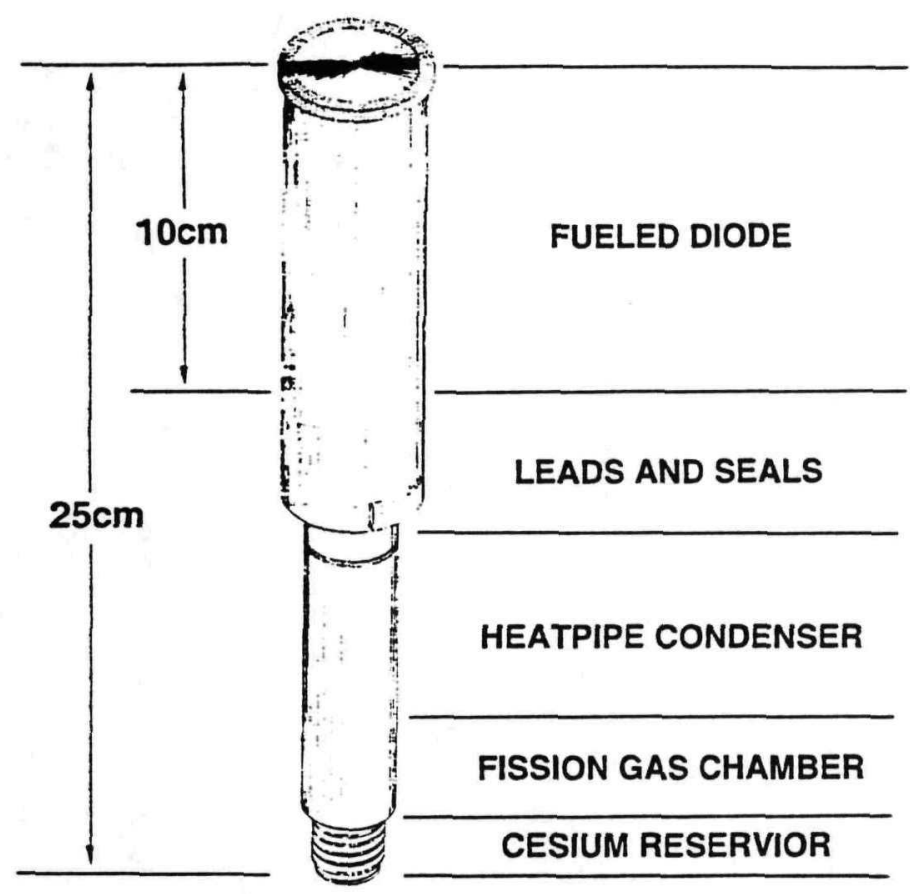

Fig.2 Thermionic Fuel Module

In addition, our design carries the concept of modularity one step further, by providing each TFM with its own fission gas collection chamber. Gaseous fission products, mostly xenon and krypton, must be vented to avoid excessive pressure buildup in the fuel chamber, particularly since even the best refractory metals have rather low creep strength at thermionic emitter temperatures. While it may be permissible to vent fission gases to vacuum in space, equipping each module with its own gas collector chamber was considered preferable, particularly for initial ground testing of the reactor.
The figure shows a view of a complete thermionic fuel module, with typical dimensions of $3.8-\mathrm{cm}$ O.D. and $25-\mathrm{cm}$ overall length. Of this, roughly $10 \mathrm{~cm}$ represents the active (fueled) length of the thermionic diode. These TFM dimensions remain relatively constant over a wide range of reactor power levels (e. g., 30 to $500 \mathrm{~kW}$ ). High power reactors employ more TFMs with smaller outer diameters.

An essential part of the modularity feature referred to above is that, after fabrication and processing, each converter module can be tested by rf-induction heating prior to reactor assembly. After performance verification, insertion of each module into its position in the reactor is essentially a "plug-in" operation, so that no welding is required after testing the converters. Moreover, even after initial tests of the assembled reactor it is still possible to replace converter modules exhibiting sub-standard performance, for example in case of errors in fuel loading. Finally, for long-term manned space missions, it may be possible to extend the useful lifetime of the reactor by periodically replacing failed converter modules, if appropriate handling equipment is provided.

\section{Reactor Arrangement}

Figures 3 and 4 present assembled and exploded views of a typical thermionic reactor, illustrating the proposed design. These figures are presented merely to provide general orientation, and to clarify the subsequent detailed discussion of various reactor components.

The specific dimensions of the reactor depend primarily on the desired power output, the fuel composition, and the maximum permissible emitter temperature. The reactor illustrated here has a $60-\mathrm{cm}$ diameter and a $50-$ $\mathrm{cm}$ height. As will be shown, a reactor of these dimensions can produce an output of $125 \mathrm{~kW}$.

As illustrated in Figure 4, the reactor consists of three major subassemblies: an upper half, a lower half, and a central section. The central section includes the control drums, radial reflector and structural side frame. The two reactor halves are bolted to the side frame; they are separated by a $0.5-\mathrm{cm}$ vacuum gap at the reactor midplane. 


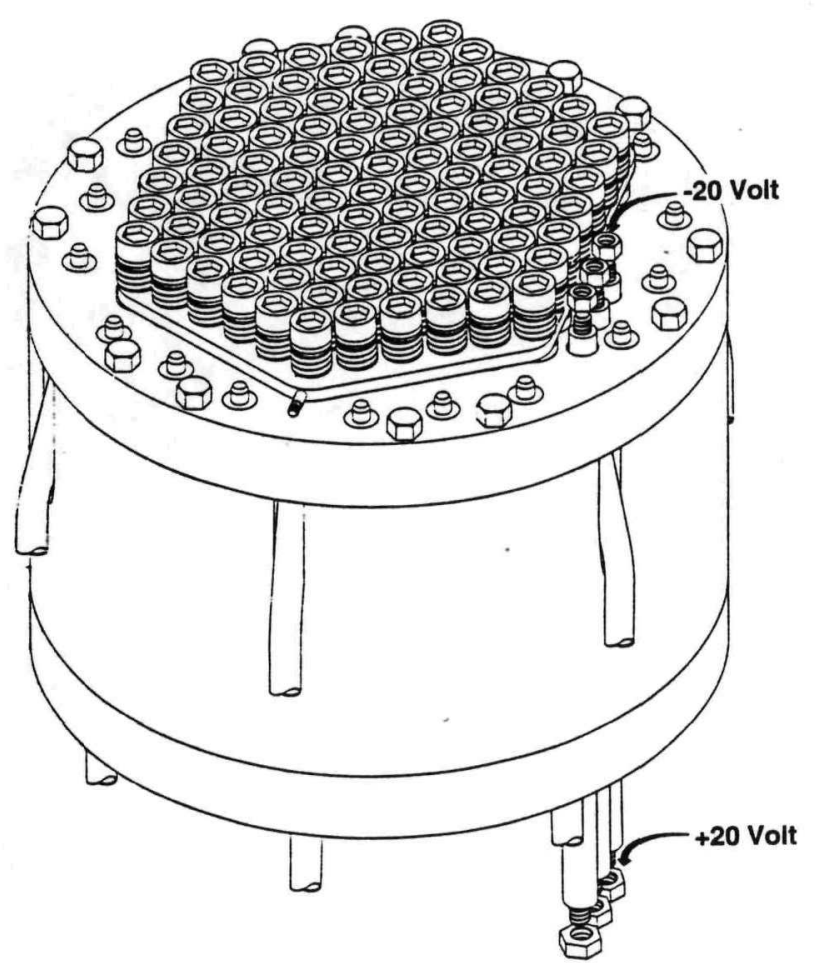

Fig.3 Assembled Reactor

Each reactor half consists of a liquid-metalcooled heat exchanger, on which are mounted the appropriate number of thermionic fuel modules, electrical connectors, and module mounting hardware. Each half also contains a small auxiliary heat exchanger for controlling the cesium reservoir temperature, which could be eliminated if integral reservoirs were used.

\section{Heat Exchangers}

The design of the main heat exchangers is illustrated by the cutaway view shown in Figure 5.

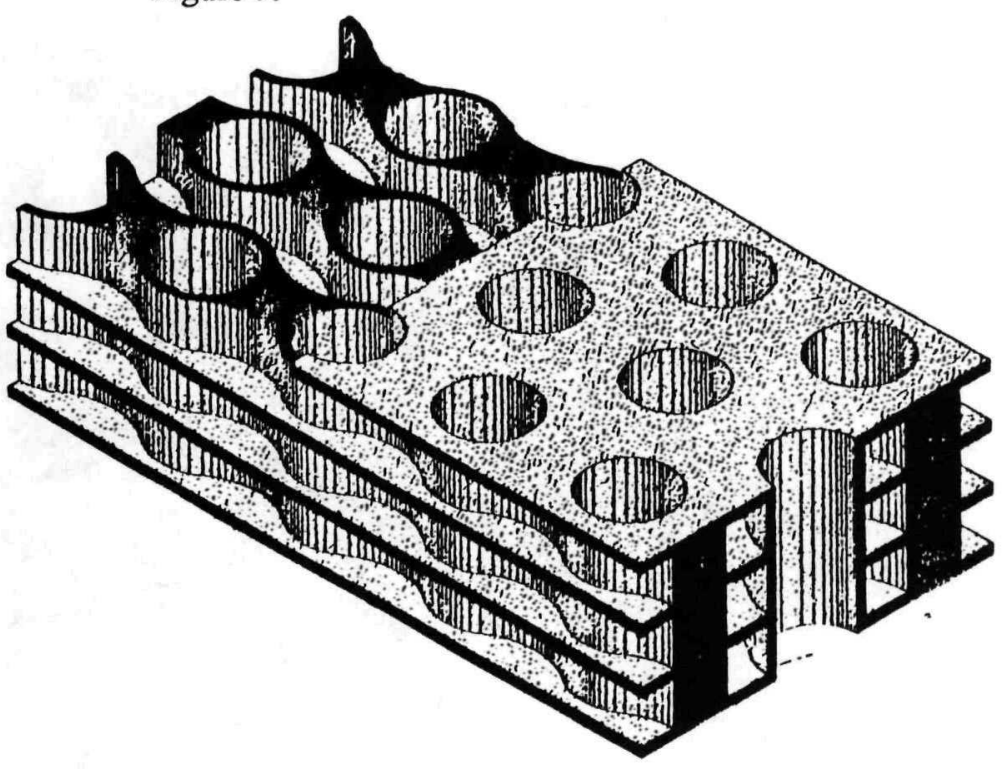

Fig. 5 Main Heat Exchanger Structure

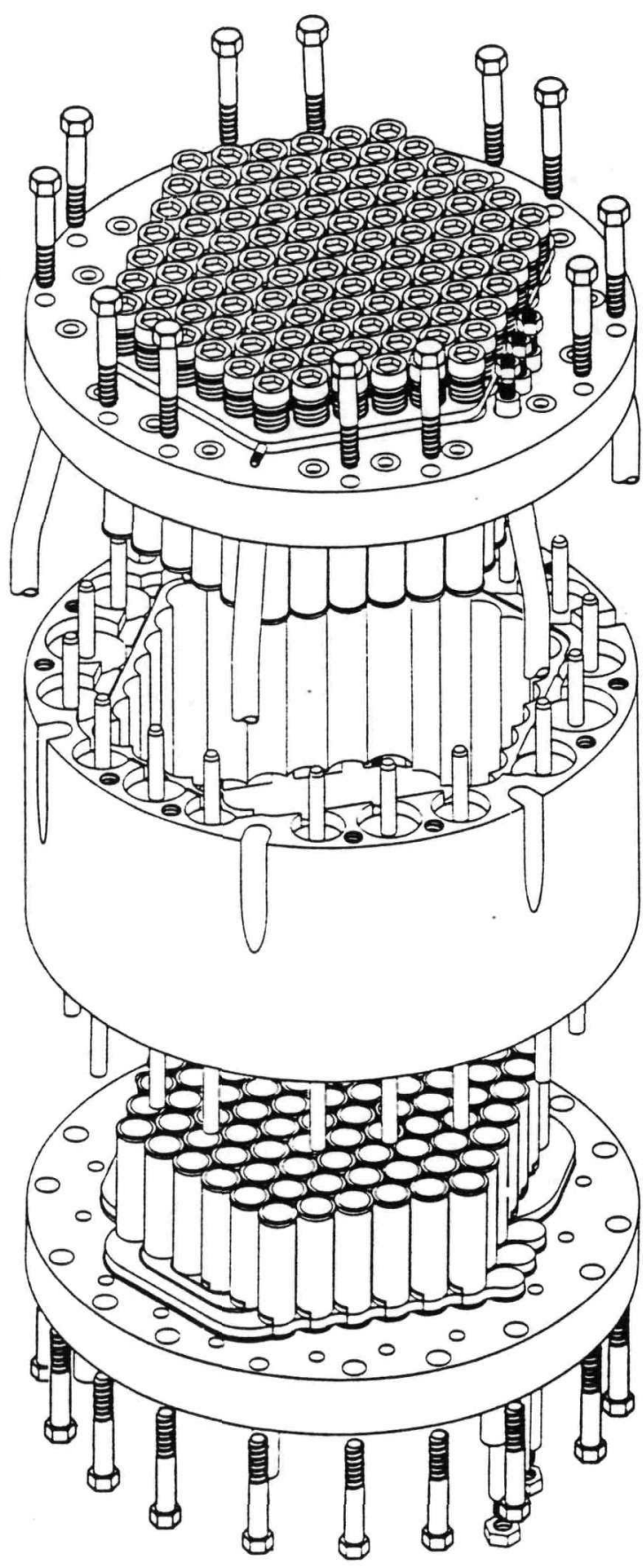

Fig.4 Dissambled Reactor

In addition to their thermal function, these heat exchangers also have a structural role since they serve as the TFM mounting plate; moreover, they also contribute to axial neutron reflection. With regard to their structural function, note that by far the highest stresses occur during the launch phase of the mission, when the heat exchangers are cold. 
The 6.3-cm thick heat exchanger has a set of $2.5-\mathrm{cm}$ diameter vertical holes into which the TFM's are inserted. Heat rejected by the TFM heatpipe condenser passes to the liquid metal (NaK) coolant. The liquid metal flows through undulating channels of rectangular crosssection.

As can be seen, the liquid coolant flows in three separate horizontal layers. Each layer of coolant ducts is connected to a separate circulating pump and radiator section. This is designed to enhance the reliability of the cooling system, because loss of one of the coolant loops would still permit the reactor to continue operating, though at somewhat reduced power output. This would not cause hot spots, since the collector heatpipes would provide a uniform axial temperature distribution.

Of course, a much simpler heat exchanger design and fabrication sequence could be used if this redundancy feature were sacrificed, or if the primary coolant delivered its heat to a secondary coolant, rather than directly to the radiators. However, one of the attributes of the present design is that it eliminates the need for a two-loop cooling system and for a primary-to secondary heat exchanger. This is so because coolant activation is quite low, since the liquid metal does not pass through the reactor core and since the axial reflectors contain no moderator.

\section{TFM Assembly}

The next two figures illustrate how each TFM is mounted on the heat exchanger. Figure 6 presents a disassembled view of the basic components of each reactor half. It shows the TFM, two series connectors, various ceramic washers, and a spring and nut for securely locking the TFM in place. In addition to the previously discussed main heat exchanger, Figure 6 also shows a smaller, low-temperature auxiliary heat exchanger. This serves to cool the cesium reservoir, as well as the mounting spring and fission gas chamber.

An assembled view of the above components is shown in Figure 7, while Figure 8 shows a view of four adjacent TFMs after insertion. The latter figure shows two alternative devices for preventing accidental shorting between

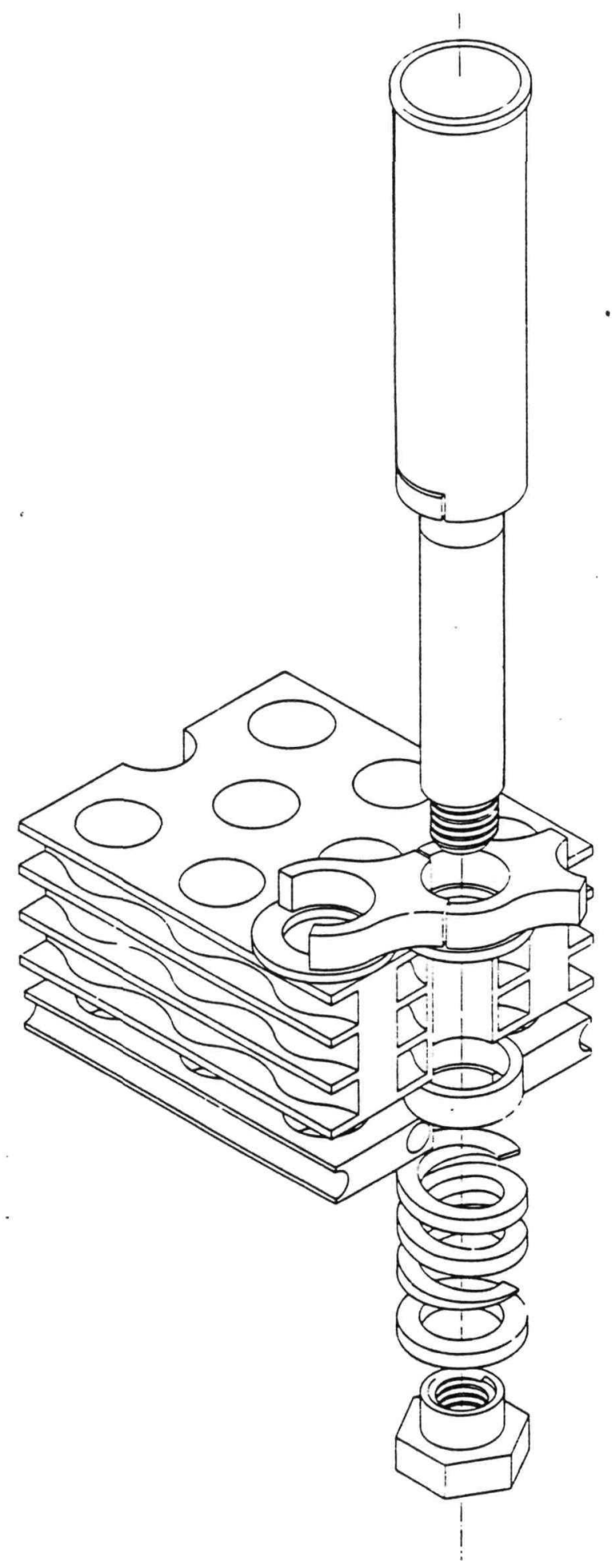

Fig.6 TFM Mounting Arrangement

neighboring modules, if needed. Neighboring TFM's are separated by vacuum gaps, which in our calculations were assumed to be $0.15-\mathrm{cm}$ thick. 

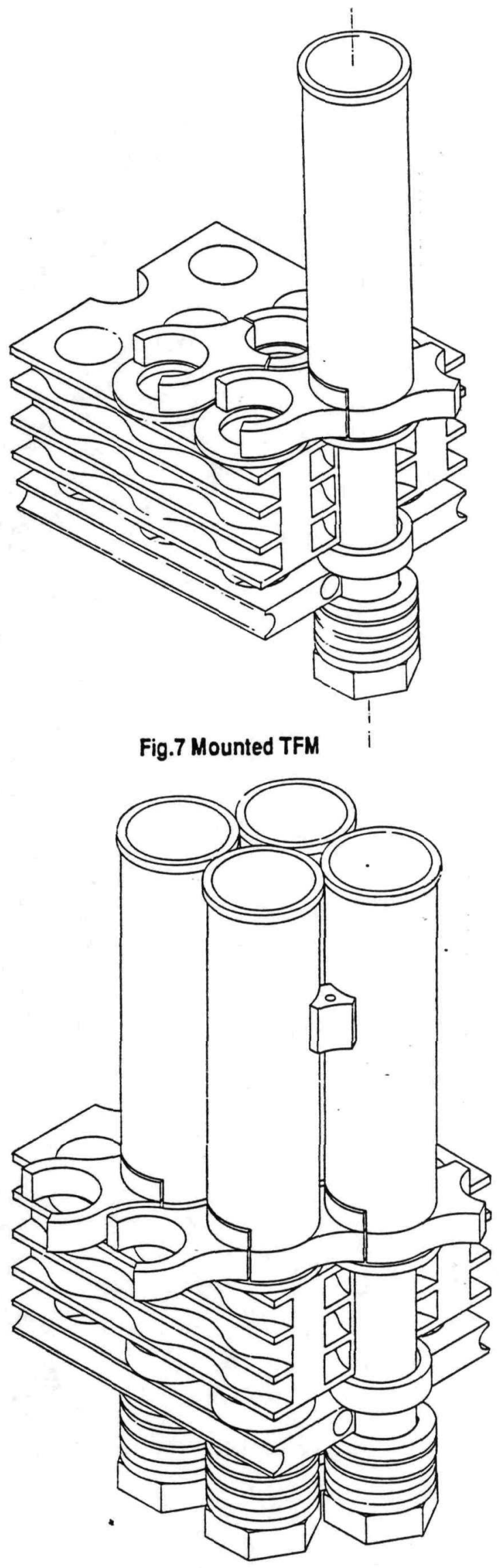

Fig.8 Relationship of Neighboring TFM's
One possible anti-shorting device is the ceramic ring shown at the top of each TFM. This will be a high temperature but essentially isothermal insulator. Test results ${ }^{7}$ suggest the use of thoria because of its excellent high temperature compatibility with tungsten. A possible alternative would be beryllia. Note that the spacer is a rather thick insulator ring, not a thin layer. Adjoining TFM's are separated by a $0.63-\mathrm{cm}$ thickness of ceramic. Also, it is not essential to maintain good thermal contact at the metal-ceramic interface, since the heat flux across it is negligible. An alternative anti-shorting device, also shown in Figure 8, is a cusp-shaped ceramic between three adjacent TFM's.

\section{DETAILED DESIGN OF THERMIONIC FUEL MODULE}

\section{Diode Region}

Proceeding to a more detailed examination of the TFM, a cutaway view of the active diode region is shown in Figure 9, and in close-up in Figure 10. The tungsten "revolver" body has six $1-\mathrm{cm}$ diameter fuel holes plus a $1.27 \mathrm{~cm}$ diameter emitter hole. The fuel-emitter assembly is separated from the thick-walled niobium collector-heatpipe by a $0.25-\mathrm{cm}$ cesium gap.

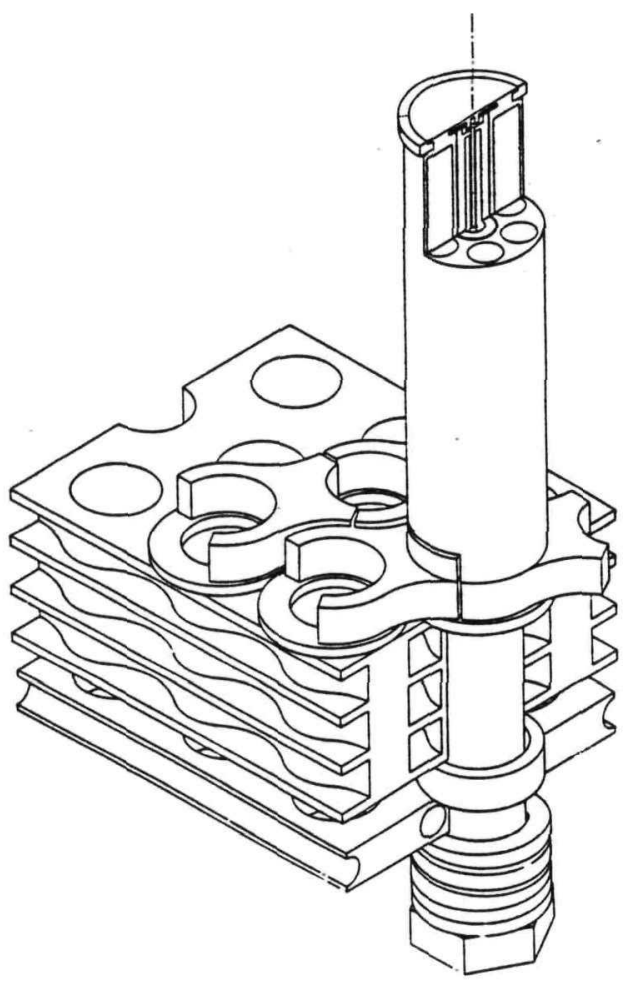

Fig. 9 Cutaway View of Diode Region 
The heatpipe wick structure is not shown. The inside of the heatpipe is filled with potassium working fluid, except for a small central tube which connects the low-temperature cesium reservoir with the diode's cesium gap.

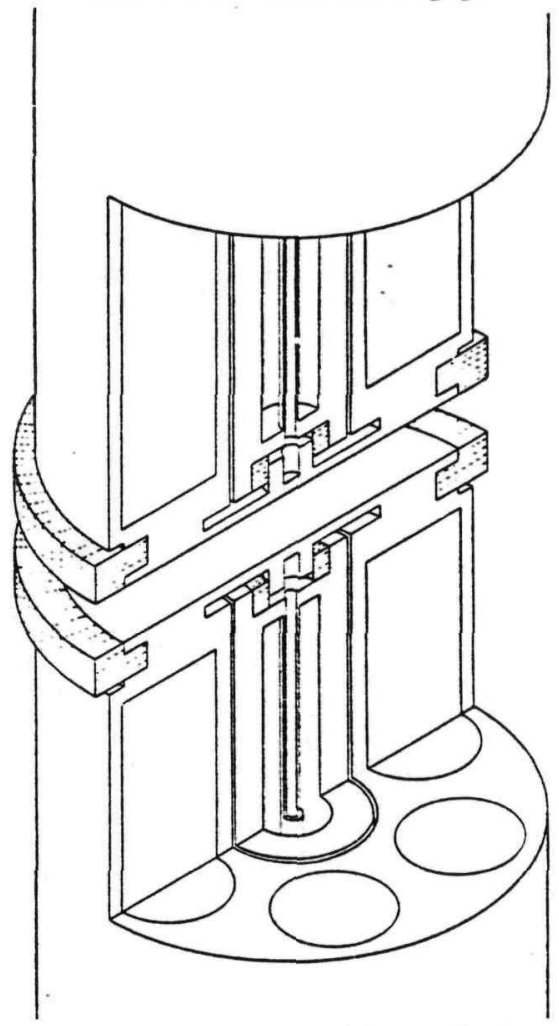

Fig. 10 Close-up View of Diode Region

Figure 10 also shows the bottom section of a TFM belonging to the upper reactor half, and illustrates the arrangement for centering the collector with respect to the emitter in each diode. This is done by means of a centering pin projecting inward from the TFM endcap, and a mating alumina sleeve bonded to the collector endcap. The sliding fit between these permits differential axial expansion of emitter and collector to be accommodated without recourse to bellows or flexible power leads. The figure does not show the small port holes or grooves in the centering pin, which are needed for communication between the cesium reservoir and the diode gap.

\section{Leads and Seals}

The emitter lead, series lead, and seal region of the TFM are shown in Figure 11, and in greater detail in Figure 12. However, the fission gas venting arrangement has been omitted to avoid confusion.

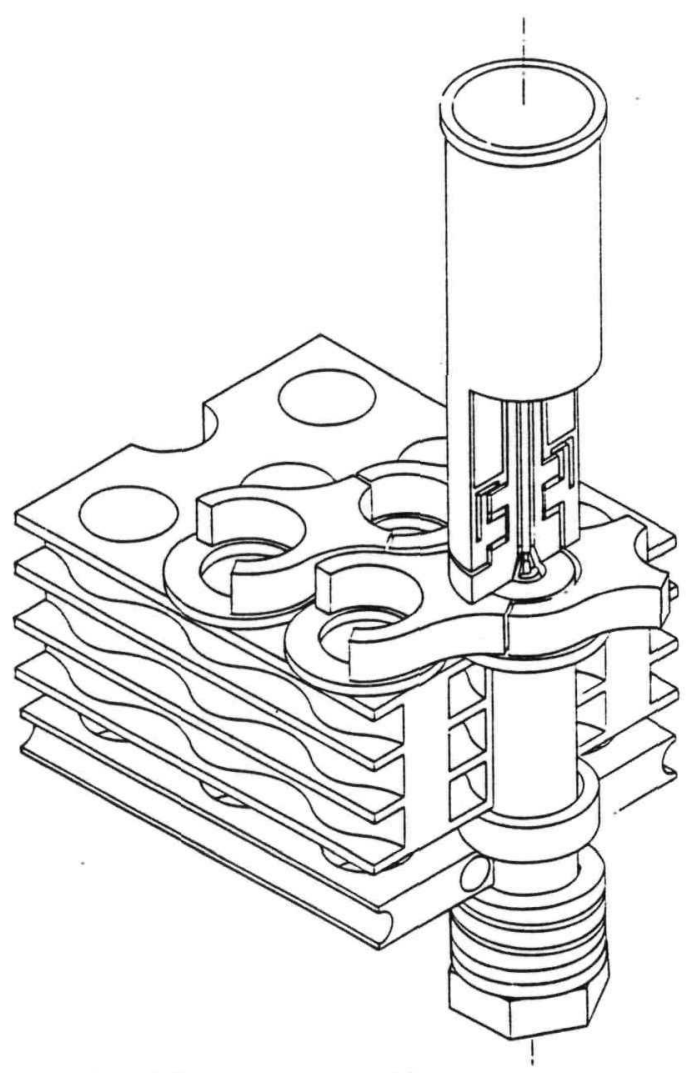

Fig. 11 Cutaway View of Seals and Leads

Each of the six fuel chambers is vented by a small tungsten snorkel tube, which extends into the isothermal cavity in the hottest part of the fuel. The passages through which the fission gas flows to the collection chamber at the bottom of the TFM are also not shown.

There are two planar metal-ceramic seals connecting the emitter and collector assemblies. The upper seal separates the cesium from an annulus containing fission gas, and the lower seal separates the fission gas from the outer

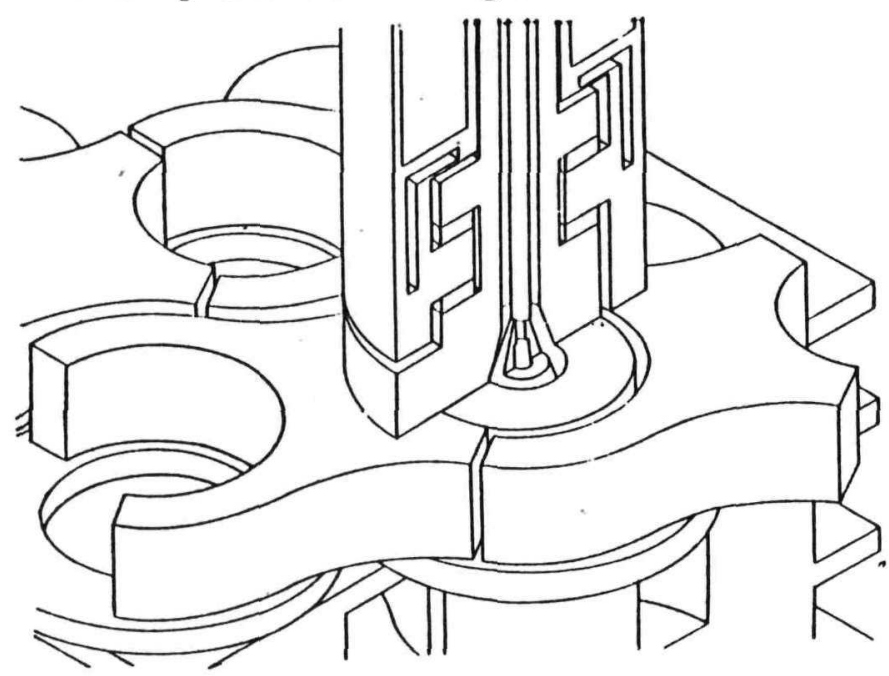

Fig. 12 Close-up View of Seals and Leads 
vacuum. Failure of the lower seal in a particular TFM would permit continued operation, with its fuel element vented to space. Failure of the upper seal would permit fission gas to enter the cesium gap. The affected TFM could still be operated, but at a lower power output because of the adverse effects of fission products on diode performance. Only if both seals were to fail in a particular TFM would the diode lose its cesium, leaving it essentially in an open-circuit condition.

The planar seals employ either metallized ceramics or graded cermets. The former would be bonded to the metallic members by brazing or by diffusion bonding. The cermet type of seal, which has proved particularly successful in our laboratory tests, is made by the hot isostatic compaction of graded layers of mixed niobium and alumina powders ${ }^{8}$ in a high pressure autoclave.

Figure 12 also illustrates the manner in which series connections between diodes are effected. All series connections are between adjacent TFMs, except for the turn-arounds at the core periphery. Electrical contact to the TFM is made at the coplanar bottom faces of emitter and collector flanges, which mate with the upper faces of their respective series connectors. In all cases, the emitter flange extends over 240 degrees of the TFM periphery, and the collector flange covers 120 degrees of the circumference. Contact pressure is maintained by means of the locknut and spring at the bottom of the low temperature auxiliary heat exchanger.

This type of contact is expected to be adequate, at least for initial ground testing of the reactor. Whether it would also be good enough for long-term operation at collector temperature remains to be determined. If not, it may be necessary to braze the contacting surfaces after completion of ground testing and replacement of sub-standard TFMs. This also applies to the slip fit between the TFMs and the heat exchanger mounting holes.

If it should prove necessary to braze these joints as the final step in preparing the reactor for launch, this could be accomplished by first precoating the appropriate TFM surfaces with a suitable braze alloy such as copper. After completion of reactor testing, all the braze joints would then be made simultaneously. This would be done by temporarily raising the liquid metal in the heat exchangers to the brazing temperature, using the high thermal conductance of the heatpipes to raise the temperature of the TFMs.

\section{Heatpipe}

Figure 12 shows the beginning of the heatpipe transition section, where the vapor passages goes through a conical expansion to a larger diameter. This is shown much better in Figures 13 and 14 which present cutaways of the TFM heat rejection region. By more than doubling the heatpipe O.D., the heat flux at the TFM-to-heat exchanger interface is cut in half. Neutron leakage through the heatpipe vapor passage is substantially reduced by inserting a solid neutron reflector plug, leaving an annular opening as shown.

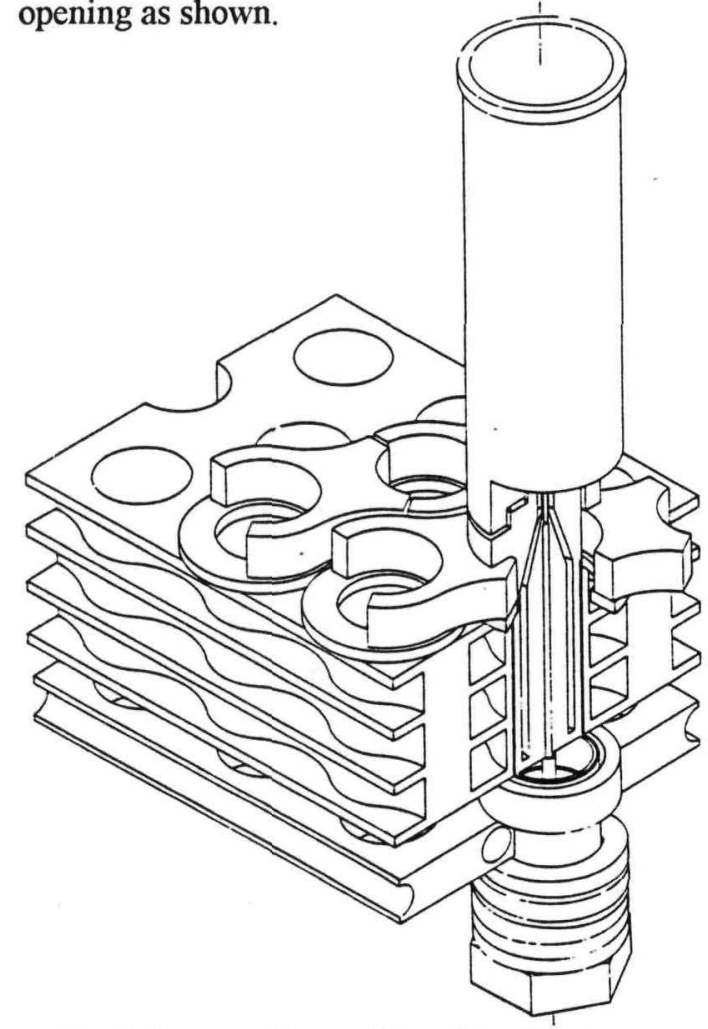

Fig. 13 Cutaway View of Heat Pipe Condenser

Since the conical expansion section is essentially adiabatic, there is no need for a porous wick in this region. A solid, thin-walled, conical transition section connects the smalldiameter, cylindrical wick in the collector and the large-diameter cylindrical wick in the condenser region. (None of these are shown in the picture). Liquid condensate returns through 
the thin annulus between the conical transition and wicks and the inner wall of the heatpipe-collector.

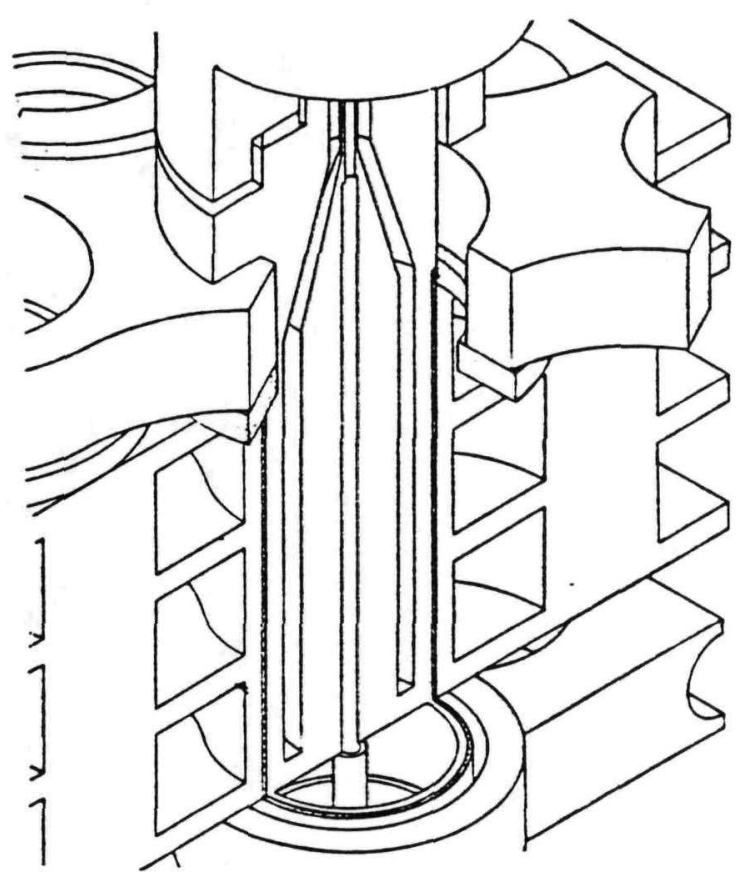

Fig.14 Close-up View of Heat Pipe Condenser

The cylindrical wicks are fabricated by swaging multiple wrappings of fine columbium screen between coaxial mandrels. ${ }^{9}$ This reduces the effective pore size, and increases the surface tension driving force of the heatpipe. Under these conditions, the thermal conductance of the heatpipe is limited not by the available pumping power, but rather by sonic flow limitations (choking) of the heatpipe vapor. The sonic heat conductance limits of cesium and potassium are approximately equal at typical collector temperatures; both are much superior to sodium. Our design assumes the use of potassium as the working fluid, because of its higher thermal conductivity. Typically, the heatpipe vapor in our design has a maximum Mach number of 0.3 , which is well below the velocity where significant deviations from isothermality occur. ${ }^{10}$

A particularly interesting heatpipe structure is achieved by providing axial grooves along the inner surface of the heatpipe, and bonding the wicks to the shoulders of these grooves. Thus, each groove is in effect an independent redundant heatpipe, providing reliability against the possibility of local wick failure.

\section{Electrical Insulation}

Figure 14 also presents a schematic view (by means of dashed lines) of the insulating coating on the outer surface of the heatpipe condenser. This insulator is required to electrically isolate the individual TFMs from the liquid-metalcooled heat exchangers, which operate in common at the ground potential of the vehicle structure.

The insulating layer through which the heat rejected by the diode passes to the coolant is a crucial component of the thermionic reactor, since this relatively thin coating $(0.025-\mathrm{cm})$ must maintain mechanical integrity, electrical insulation, and thermal conductance over the lifetime of the reactor. Note that the design described here avoids exposure of this insulating layer to the diode's cesium atmosphere, in contrast to the commonly considered "flashlight" design, where cesium-filled cracks in the sheath insulator can lead to low-voltage breakdown and shorts-to-ground at typical collector operating temperature. ${ }^{11,12}$

To reduce this danger, reactors in which the insulator layer is exposed to cesium must be designed to operate at very low output voltages (10-15 volts), which of course increases the weight and power loss of the busbars that connect the reactor to the power conditioners. To reduce this penalty, power plant designs based on such reactors usually locate the power conditioners immediately behind the shield, i. e., ahead of the high temperature radiator. However, for unmanned space missions the power conditioners are usually as radiation-sensitive as the payload. Since the above arrangement loses most of the benefit of geometric attenuation, it increases the required shield weight.

The higher voltages made possible by not exposing the sheath insulator to cesium are desirable not only for avoiding the above problems, but also because they help to raise the efficiency of the power conditioners. A relatively small change in the power conditioner efficiency (e.g., from $88 \%$ to $92 \%$ ) can have a large effect on the size of the power conditioner radiator, which is generally comparable to that of the high temperature radiator. 
Even more important, for certain space missions (not involving electrical propulsion ion engines) most of the load demand may be for D.C. power, e. g., in the 28 to 56 volt range. For these applications, the higher voltages permitted by the TFM concept makes it possible to design a system in which the reactor feeds its output directly to the load, without power conditioners. Of course, provisions would have to be made for power distributions and control, but this may be possible without the need for D.C.-to-A.C. conversion, with its attendant weight, size, and efficiency penalties.

In the present design the insulator coating is not only located on the outside of the TFM, and therefore unexposed to the diode's cesium atmosphere; it is also removed from the reactor core itself, where neutron induced radiation damage of alumina ${ }^{13}$ would be highest. Instead, the insulator coating in this design is located in the heat exchanger, where the damage-causing fast neutron flux is at least an order of magnitude lower than at the reactor midplane.

The insulating layer is fabricated to form a metal-ceramic-metal tri-layer. The alumina insulator is first applied to the outside of the heatpipe condenser, the coating is then jacketed by a thin-walled columbium sheath, and the assembly is isostatically pressure bonded in a hot-gas autoclave. This method has proved quite successful in our laboratory studies. ${ }^{14}$

\section{Fission Gas Collection and Cesium Reservoir}

Finally, at the bottom of Figure 14 we can look into the top of the fission gas collection chamber. This is shown more clearly in Figures 15 and 16 . The chamber volume is sized so as to develop a gas pressure of $3 \mathrm{~atm}$. in 10,000 hours, assuming complete release of all xenon and krypton from the fuel. Use of a charcoal trap would result in a much smaller collection chamber and/or lower pressure buildup. However, such charcoal traps operate efficiently only at very low temperatures, which would be difficult to maintain on a spacecraft.

Figure 16 illustrates how the auxiliary heat exchanger cools the fission gas chamber, locknut, spring, and cesium reservoir. As

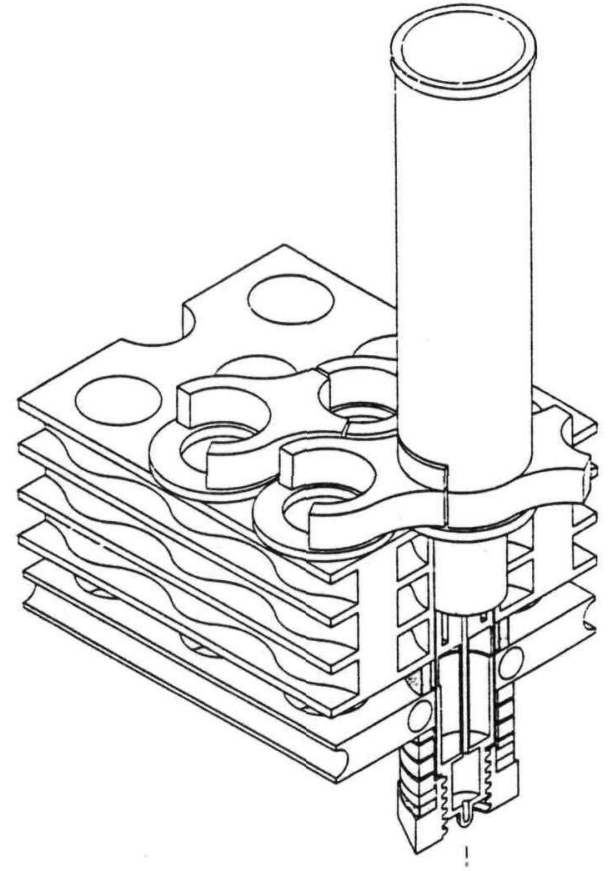

Fig.15 Cutaway View of Gas Chamber and Cesium Reservoir

shown, the outside of the cesium reservoir is threaded, to engage the locknut. The auxiliary heat exchanger operates somewhat below the desired cesium reservoir temperature $\left(\sim 360^{\circ} \mathrm{C}\right)$. If desired, final adjustment of the cesium pressure in each TFM can be effected by thermally trimming each reservoir with a small electrical heater. For zero-gravity space missions, the reservoir is filled with a porous structure, to retain the liquid cesium by surface tension. (Alternatively, an all-solid cesiumgraphite reservoir operating at a much higher temperature may be employed for zero-g operation.)

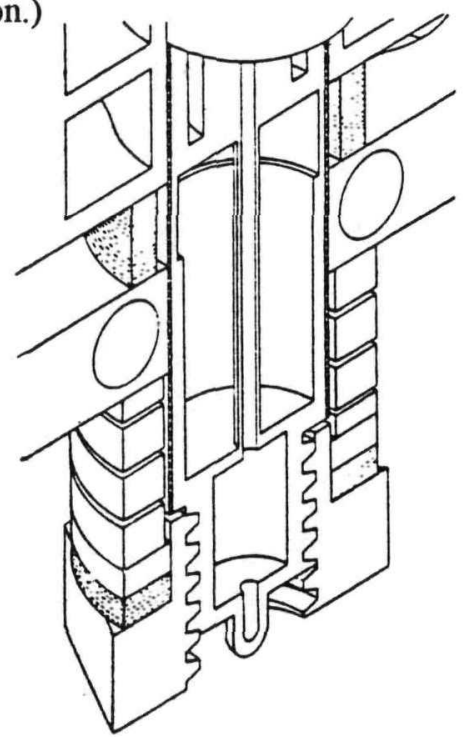

Fig. 16 Close-up view of Gas Chamber and Cesium Reservoir 
A cross-sectional view of the complete thermionic fuel module is presented in Figure 17, which shows the TFM volume occupied by the cesium and by the potassium working fluid in the heatpipe, as well as the fission gas path between the fuel chambers and the gas collection chamber.
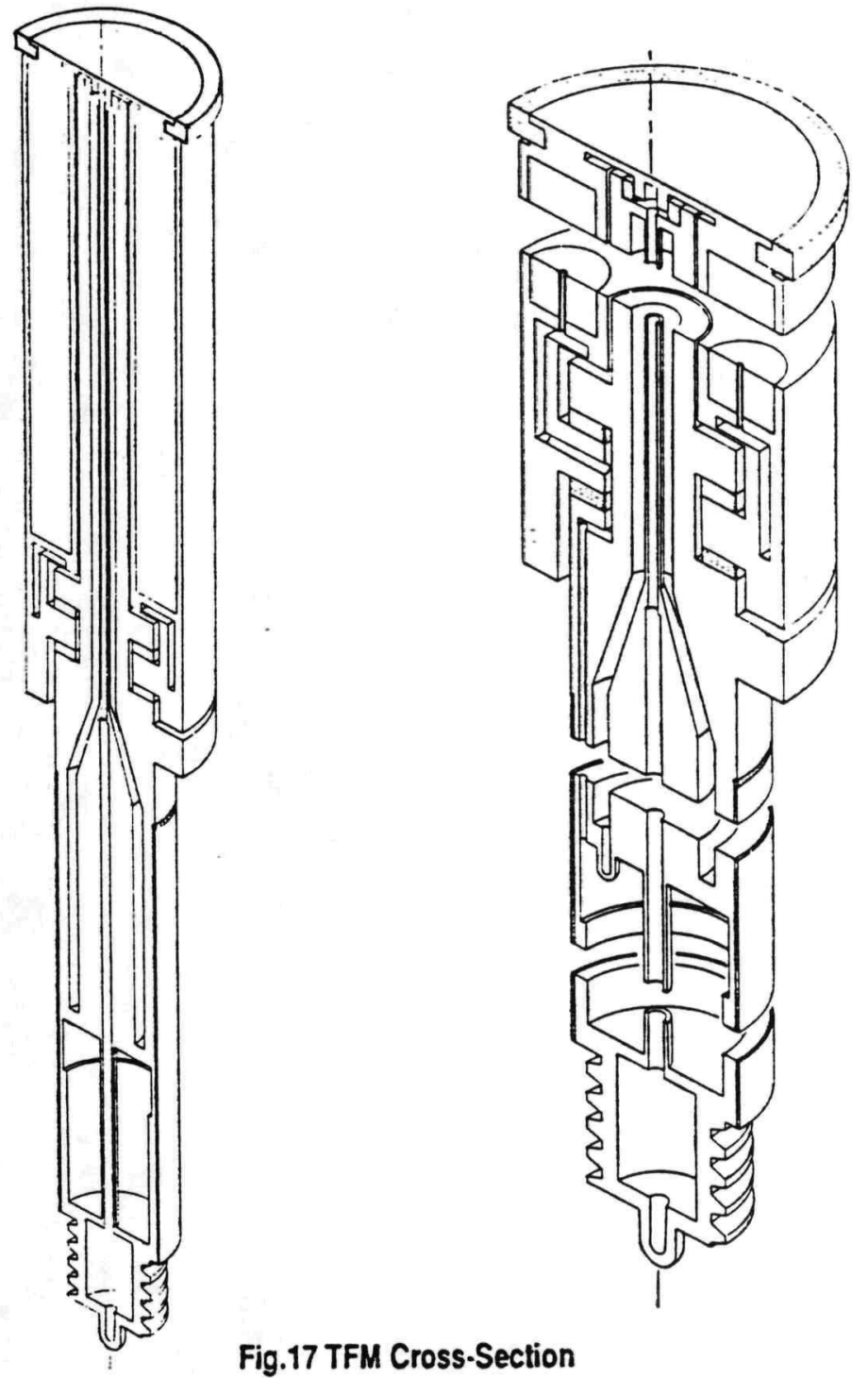

Fig.17 TFM Cross-Section

\section{Temperature Distribution}

A typical temperature distribution in a diode employing an annular cermet fuel element is shown in Figure 18. As can be seen, the radial temperature drop in the fuel $\left(\sim 50^{\circ} \mathrm{C}\right)$ is much smaller than the axial temperature drop. Also, note that the ceramic seals are below $900^{\circ} \mathrm{C}$, and even the ceramic sleeve used for centering the collector operates below $1000^{\circ} \mathrm{C}$.

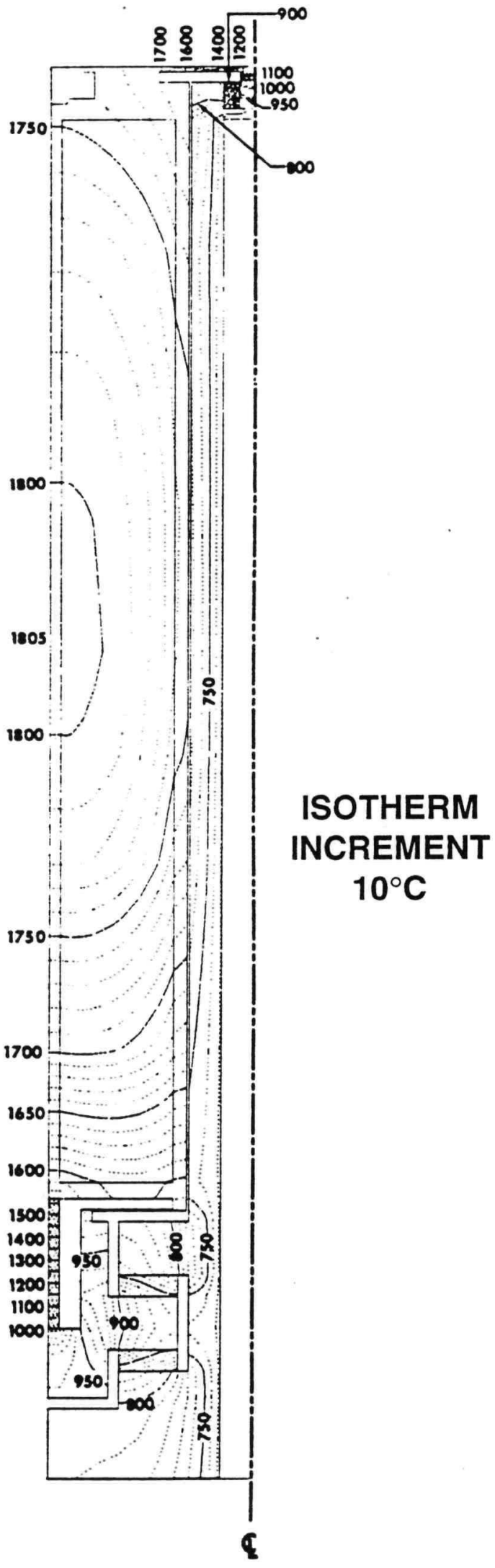

Fig.18 Temperature Map of Cylindrical Cermet Module 
An analogous, detailed temperature map for a "revolver" fuel element was not produced, since that would require a fine-meshed, three-dimensional thermal analysis program. However, Figure 19 shows an $r-\theta$ temperature map of a typical hexagonal "revolver" element. Here too, the radial temperature gradients are seen to be small. Also, note that the maximum temperature in the $\mathrm{UO}_{2}$ fuel $\left(\mathrm{k}=0.02 \mathrm{w} / \mathrm{cm}^{\circ} \mathrm{C}\right)$ is only $170^{\circ} \mathrm{C}$ above the emitter temperature.

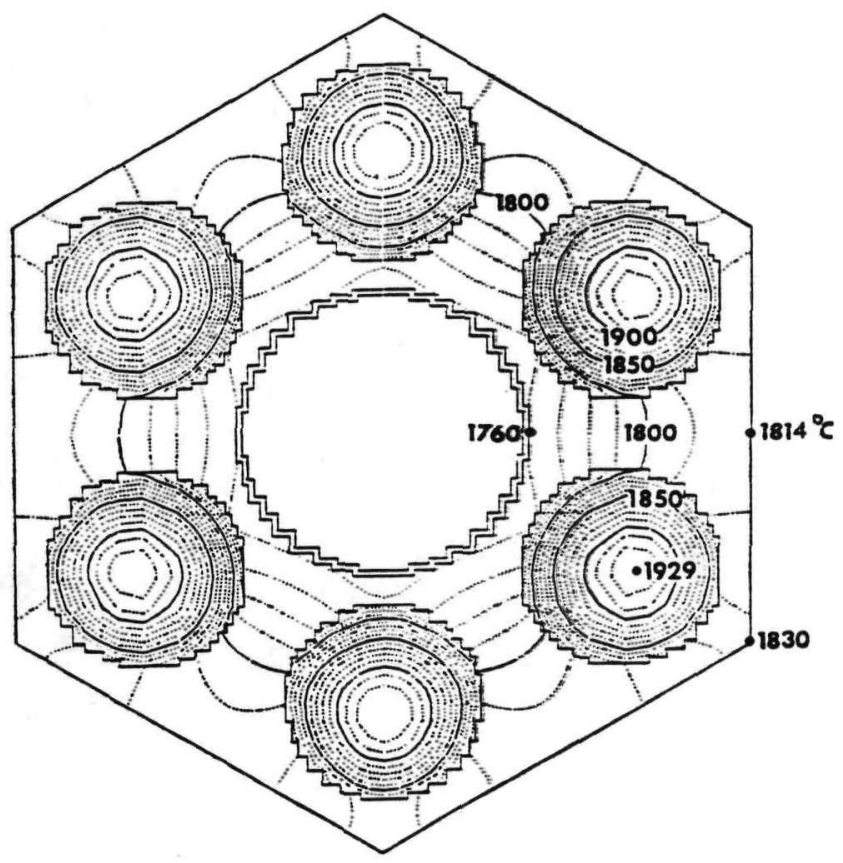

Fig.19 Temperature Map of Revolver Fuel Element

\section{TFM Testing}

Time does not permit a detailed discussion of TFM fabrication and processing procedures, except to note that all refractory metal joints are made by electron beam welding, and that both the heatpipe and the complete TFM can be subjected to intensive testing before acceptance.

For example, it may be desirable to measure the thermal conductance limit of each heatpipe, before and after an extended lifetest at operating temperature. This would screen out heatpipes without adequate performance margin, or those that exhibit any significant performance degradation during lifetest.

Similarly, each complete TFM can also be subjected to extended lifetesting under realistic operating conditions. Since external-fuel diodes readily lend themselves to electrical heating by rf-induction, these lifetests can take place out-of-pile, rather than in a test reactor. This avoids the need for subsequent assembly of radioactive components.

\section{$\underline{\text { Reactor Assembly Sequence }}$}

The 1970 report $^{6}$ from which this design description is excerpted included a detailed description of a method for fabricating the heat exchangers (See Figure 3) on which the TFMs are mounted, including the connections of the three independent liquid-metal coolant loops in each. It also described the installation of the series-parallel network connections, the thermal insulation assembly, the twelve control drums, and the final joining of the two reactor halves and closure of the reactor depicted in Figures 3 and 4. These descriptions have been omitted here because of their excessive length.

\section{ANALYSIS}

This part of the paper examines different ways of arranging the electrical network within the reactor core, illustrates the approach used in analyzing the thermionic reactor, and presents typical sizes, weights and other characteristics for a wide range of reactor power levels.

\section{Electrical Arrangement and Power Flattening}

The TFMs in the reactor are connected in a series-parallel matrix. The purpose of the parallel connections is to reduce the output penalty for open-circuit failures of individual diodes.

One of our previous studies ${ }^{15}$ had indicated that the performance penalty resulting from non-uniform heat generation rates is significantly lower in a group of parallel diodes (operating at the same voltage) than in a similar group of series-connected diodes (same currents and electron cooling rates). This suggests that, as far as possible, series connections be made only within a given ring of TFMs, with only parallel connections between the different rings. Accordingly, the electrical arrangement illustrated in Figure 20 was selected. 


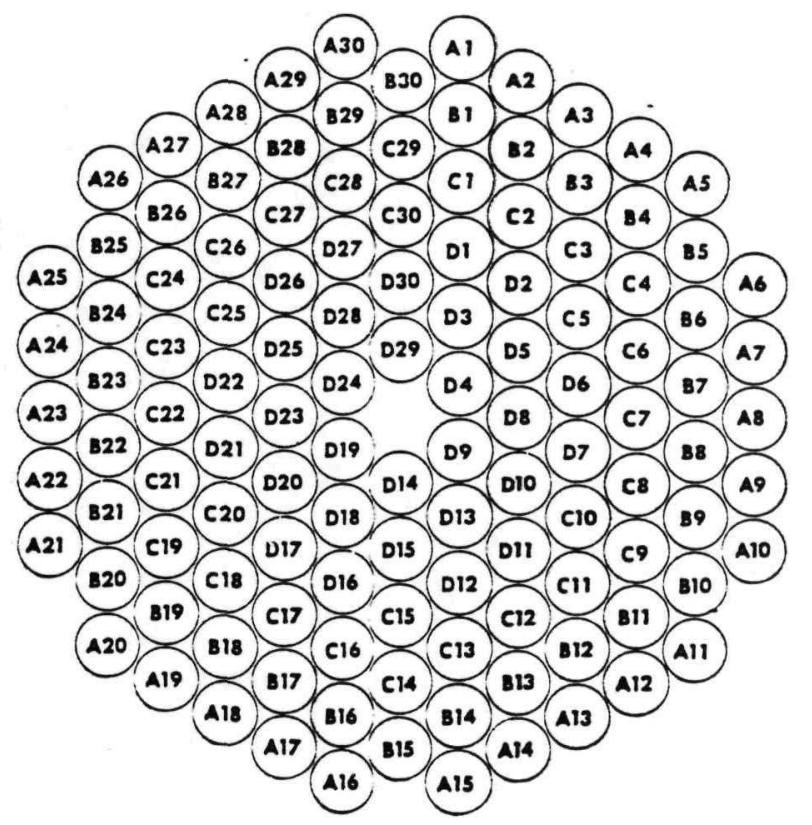

Fig.20 Network Arrangement

In the design illustrated, each reactor half has $120 \mathrm{TFMs}$, arranged in $4 \times 30 \mathrm{parallel} / \mathrm{series}$ matrix as indicated by the letter and number designations. As can be seen, all series connections are between adjacent TFMs, as are all but a few of the parallel connections.

With the arrangement shown in Figure 20, different currents can pass through the inner and outer rings of TFMs. This has two major advantages: First, the power flattening problem is alleviated because the outer TFMs experience less electron cooling than the inner ones. And second, since currents need no longer match, there is no need to maintain a uniform emitter diameter throughout the reactor. Thus, instead of power flattening by widening the vacuum gaps between TFMs in the middle of the reactor, we can maintain a uniform fuel O.D. throughout, but increase the emitter diameters of the inner rings of TFMs. Increasing these emitter diameters not only raises the total emitter surface and power output of the reactor; it also produces a more uniform temperature distribution by increasing the electron cooling rate in the inner rings of TFMs.

\section{Analytical Approach}

The techniques used to analyze the thermionic reactor will be illustrated with reference to the specific reactor arrangement depicted in Figure 20. Although an iterative approach must be used to home in on a solution satisfying the various nuclear, thermal, and electrical constraints, only the final iteration is presented here.

The case examined is based on cylindrical cermet fuel elements (see Figure 1), as were most of the designs analyzed in this study. TFMs employing bulk $\mathrm{UO}_{2}$ filled revolver fuel elements are somewhat more difficult to analyze, because in that case the analysis must take account of fuel redistribution within the TFM as a result of $\mathrm{UO}_{2}$ vaporization. However, enough such cases were studied to demonstrate that for a given reactor power the use of revolver elements results in a somewhat smaller and lighter reactor than the use of cermet fuel elements.

The design represented by Figure 20 is based on 240 TFMs arranged in a quasi-cylindrical reactor core. For the purpose of the nuclear analysis, the core was treated as consisting of four coaxial cylindrical shells (A, B, C, D). All nuclear calculations employed $\mathrm{DOT}^{16}$, a two-dimensional multi-group transport code using the P0 and S4 options. Twenty-six group FCC $^{17}$ cross-sections were collapsed to thirteen groups by combining some of the less populated low-energy groups. The use of $93 \%$-enriched U-235 and natural tungsten was assumed.

In the specific design examined here, the cylindrical fuel modules have outer diameters of $4.0 \mathrm{~cm}$, and are separated by $0.15-\mathrm{cm}$ vacuum gaps. The emitter diameters (from inner to outer TFM rings) were $0.75,0.70,0.60$, and 0.50 inch $(1.91,1.78,1.52,1.27 \mathrm{~cm})$ corresponding to fuel fractions of 57, 59,64, and 68 volume percent in the four rings. The fuel here contains a uniform 60 volume $\% \mathrm{UO}_{2}$, with no axial zoning. The collectors, made of $\mathrm{Cb} / 1 \% \mathrm{Zr}$, contain $0.63-\mathrm{cm}$ diameter vapor channels.

The results of the nuclear calculations are shown in Figures 21, 22, and 23, which display the axial variation of relative fission density per unit fuel volume, diode length, and emitter area, respectively. Figure 21 illustrates the wide variation of neutron flux, with a 3:1 $\mathrm{max} / \mathrm{min}$ ratio. 


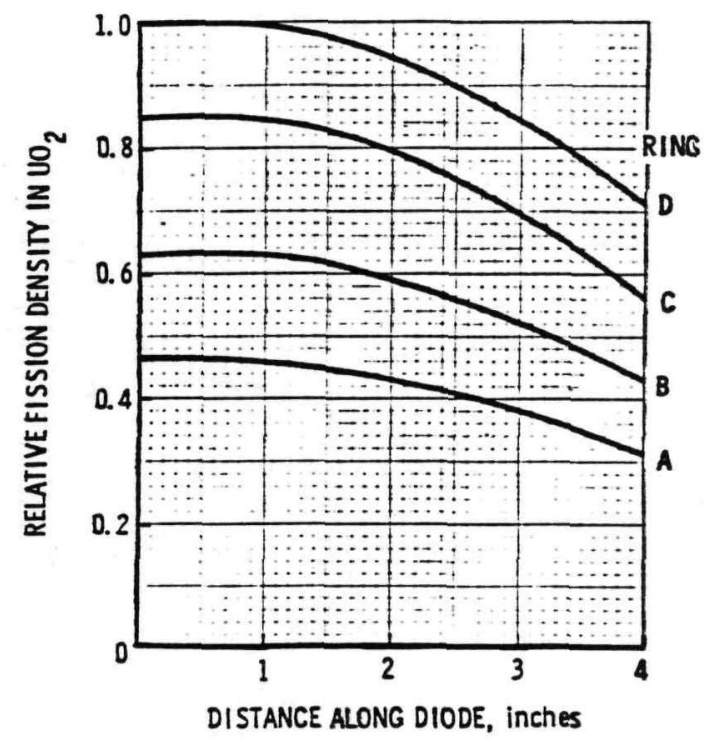

Fig.21 Axial Profiles of Fissions per Unit Fuel Volume

As, shown in Figure 22, the thermal power per unit length of TFM varies somewhat less, because the inner TFMs contain less fuel. But it is still very far from uniform.

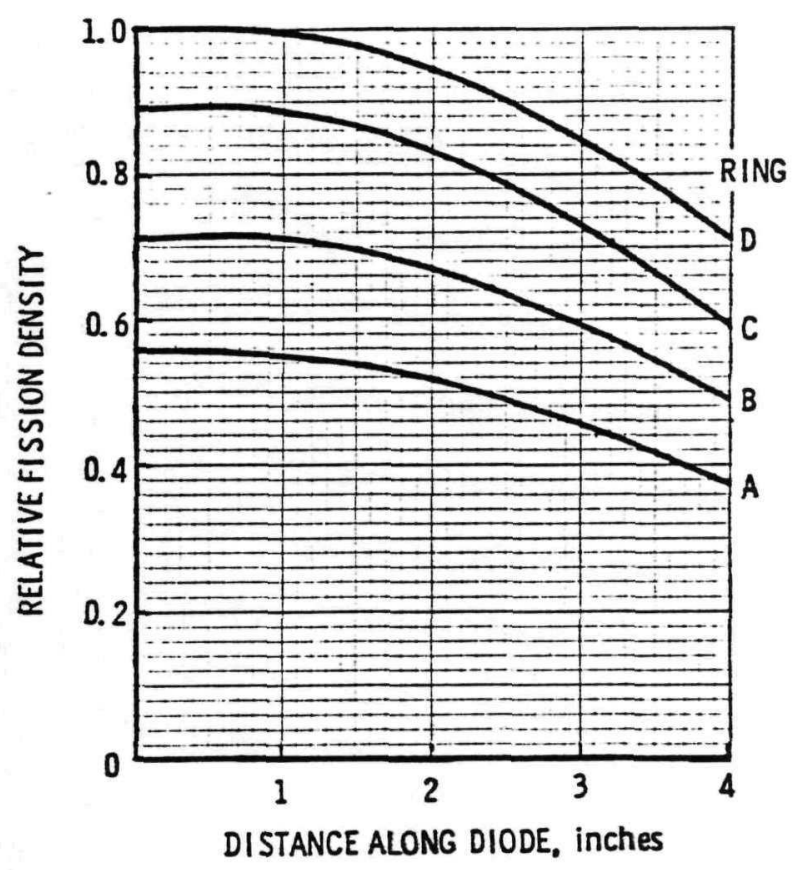

Fig.22 Axial Profiles of Fissions per Unit Diode Length

It is only when the fission rates are compared on the basis of thermal power per unit emitter area that the four curves approach each other, as shown in Figure 23.

It may be wondered why the emitter diameters are not further adjusted, in order to make the four curves of Figure 23 coincide.

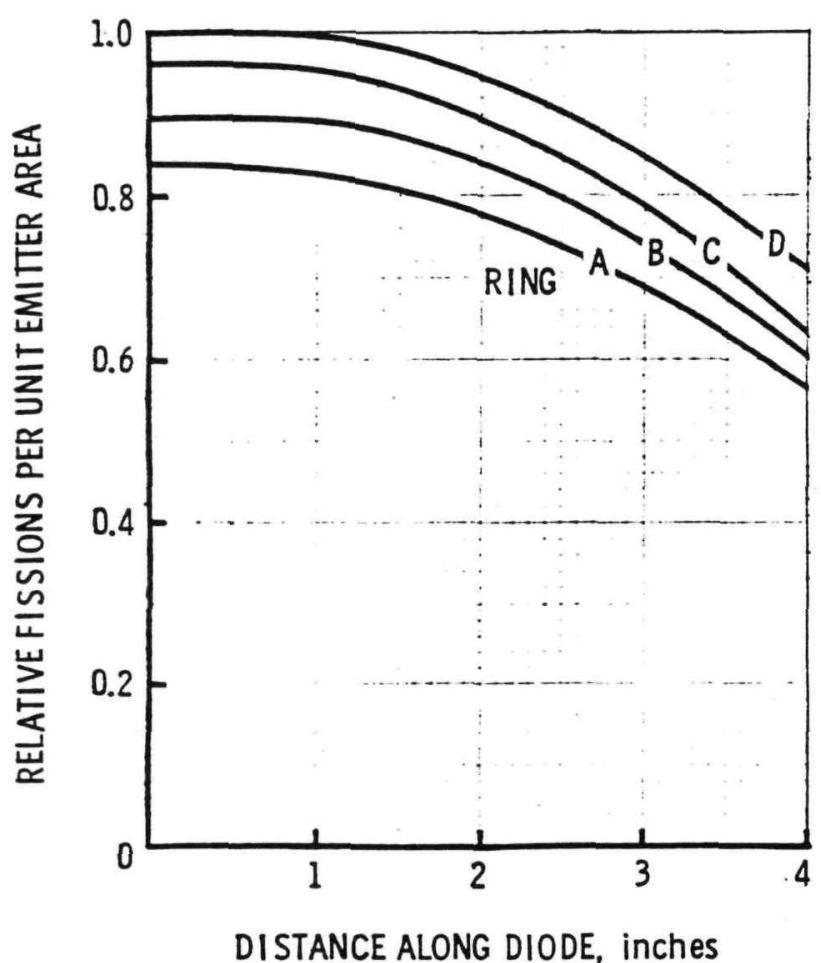

Fig.23 Axial Profiles of Fissions per Unit Emitter Area

This could be done by minor adjustment of emitter diameters. Actually, however, the zoning illustrated is optimum in that it produces the best matching of the emitter temperature profiles of the four types of TFMs.

The next step in the analysis is to choose a specific value for the thermal power of the reactor, and compute current-voltage characteristics for each type of TFM. Each point on a TFM's current-voltage characteristic requires the simultaneous solution of the two Laplacian equations shown below to compute the axial variation of emitter temperature $T$ and diode voltage $\mathrm{V}$.

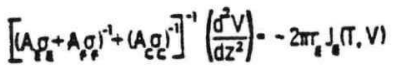

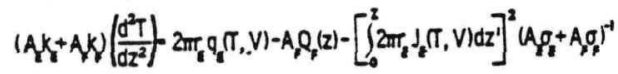

Solution of these equations and their boundary conditions was discussed in detail in an earlier report. ${ }^{18}$ All results presented in this paper assume a $0.025-\mathrm{cm}$ electrode gap, a $1000^{\circ} \mathrm{K}$ collector temperature, and a $630^{\circ} \mathrm{K}$ cesium reservoir temperature.

For a reactor thermal power of $865 \mathrm{kw}$, Figure 24 illustrates a typical solution, for a Type-A TFM at a terminal voltage of 0.634 volt. 


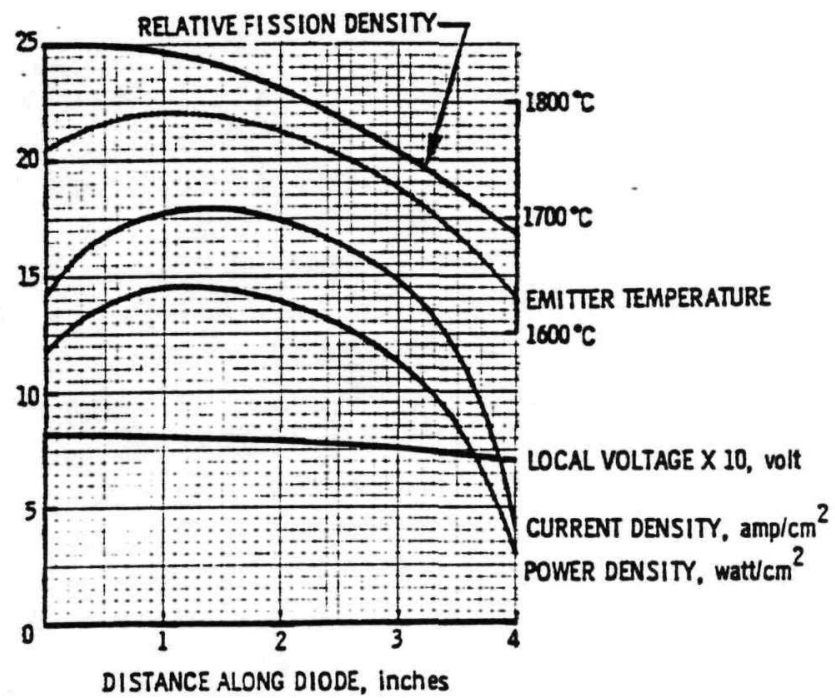

Fig.24Typical Solution of Thermal and Electrical Equations (Ring-A TFM, 0.634-volt Net Output, 865-kw Reactor Power)

As can be seen, the outer end of the diode contributes relatively little power, primarily because of heat loss to the emitter lead.

The solution shown yields one point on the TFM current-voltage characteristic. Repeating the process for other terminal voltages and other TFM types produces the four I-V curves shown in Figure 25, which are all for the same reactor power.

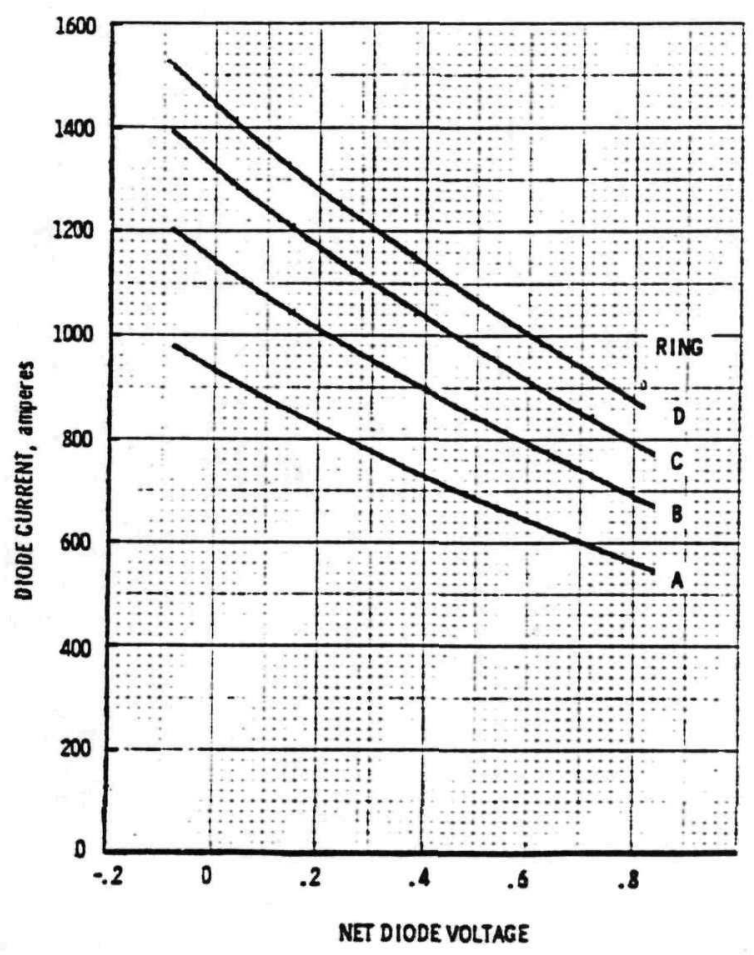

Fig. 25 Current-Voltage Characteristics of TFM's at $865-k w$ Reactor Power
Applying these characteristics to the $4 \times 60$ TFM network, we obtain the current-voltage characteristic of the reactor shown by the 865-kW curve in Figure 26.

The entire procedure is repeated for different thermal power to yield the other reactor characteristics displayed in Figure 26. The solid curves are for constant thermal power, while the dashed curves represent constant temperature of the hottest emitter point in the reactor.

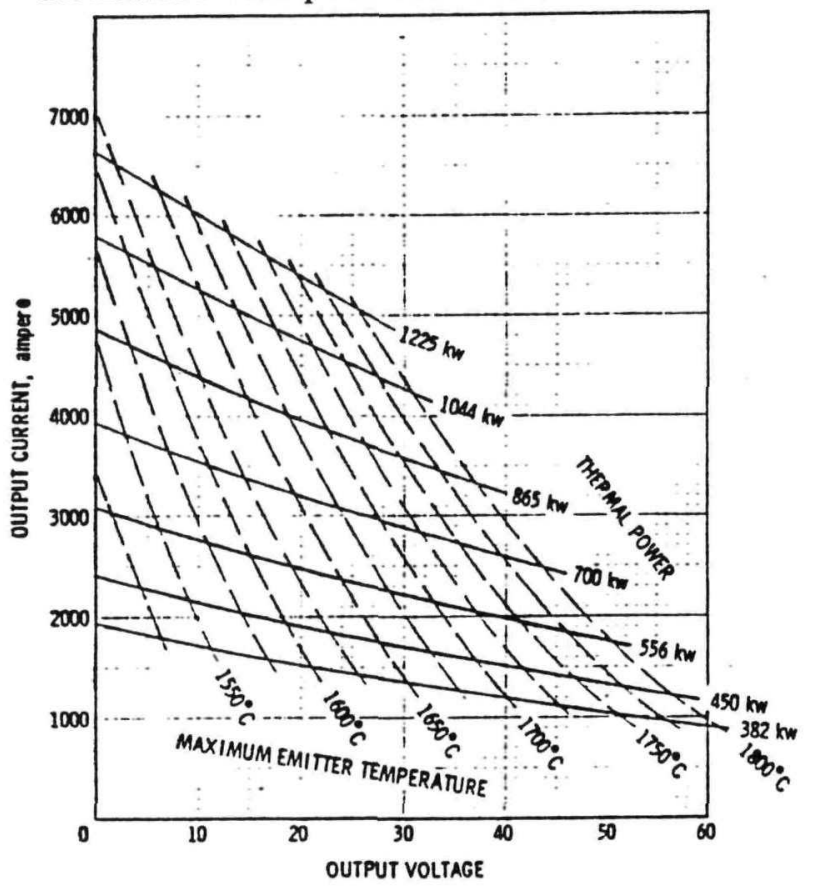

Fig.26 Current-Voltage Characteristics of 240-TFM Reactor

These reactor characteristics are particularly useful for control and safety studies. As can be seen, for a given thermal power, varying the reactor current has a pronounced effect on emitter temperature, because electron cooling represents the dominant emitter heat loss mechanism.

To aid in selecting the reactor operating point, it is instructive to display the data of Figure 26 by plotting reactor output power versus voltage. Figure 27 shows curves of constant thermal power (solid), constant maximum emitter temperature (dashed), and constant reactor efficiency (dotted). As can be seen, for a given maximum emitter temperature the highest efficiency occurs at a considerably higher output voltage than does the maximum output power. When either variable is maximized, the other variable is appreciably below its maximum value, particularly at high emitter temperature. 


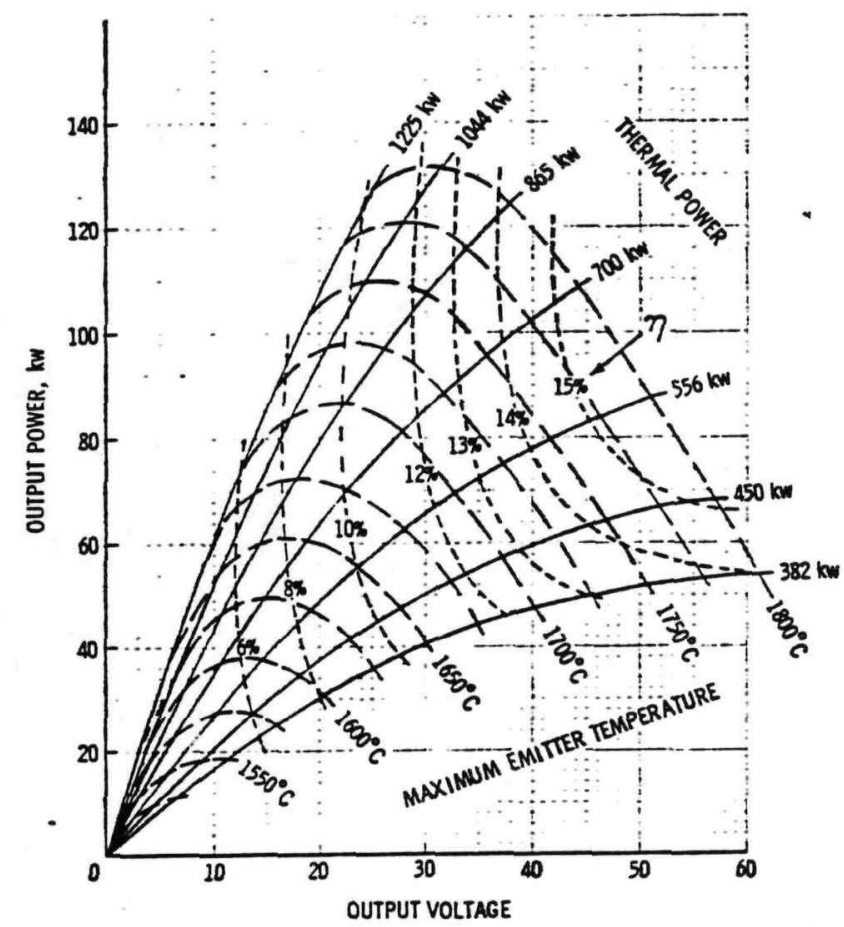

Fig.27 Performance Characteristics of 240-TFM Reactor

The trade-off between power and efficiency for the 240-TFM reactor is illustrated in Figure 28. Each curve is for a constant maximum emitter temperature, with voltage as the implicit variable. The figure shows that reactor performance is a very sensitive function of maximum temperature, at least for the assumed type of emitter (i. e., tungsten with a 4.75-ev bare work function).

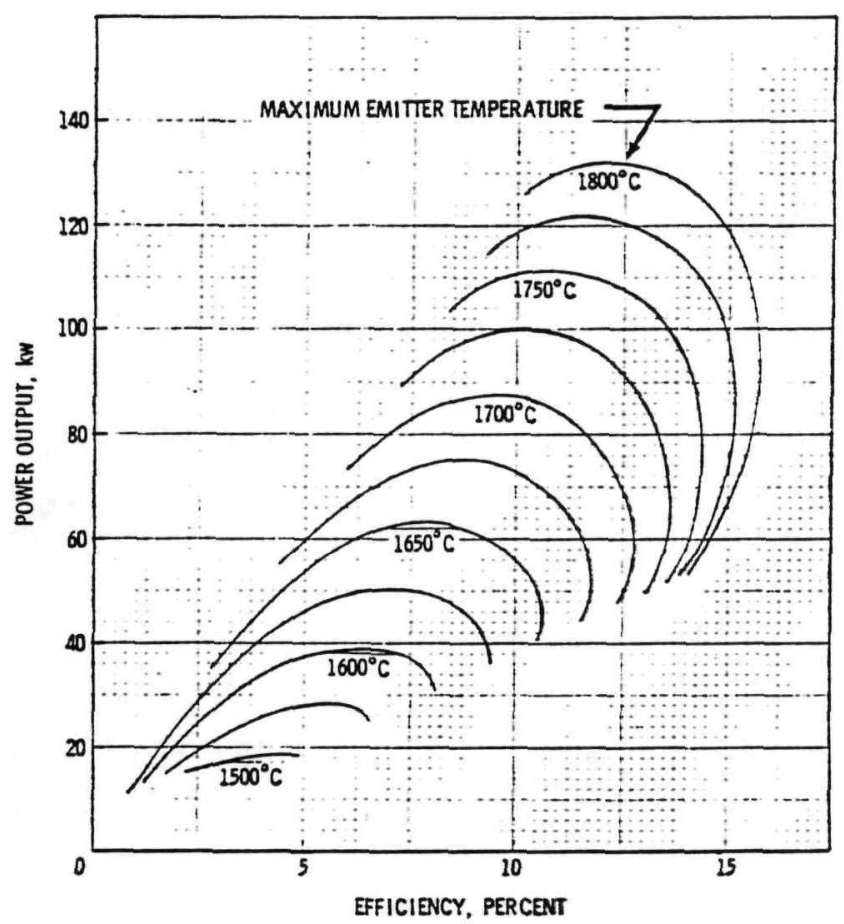

Fig.28 Power-Efficiency Trade-off for 240-TFM Reactor

\section{Analytic Results}

Similar performance characteristics were computed for the seven illustrative designs described below, to provide specific examples for a wide range of power levels, approximately from 30 to $500 \mathrm{ekw}$.

For a specified maximum emitter temperature, the specific weight of the reactor, radiation shields, and other fixed-weight components of the power plant is minimized by operating at the maximum power point on the power-efficiency characteristic. On the other hand, the specific weight of the radiator, pumps and plumbing is minimized by operating at the maximum efficiency point on the characteristic. Clearly the specific weight of the complete power plant will be smallest at some intermediate point on the constant temperature characteristic.

To illustrate this graphically, it is necessary to calculate the weight of various power plant components outside the thermionic reactor. However, our AEC-supported design studies ${ }^{19}$ were largely confined to the thermionic reactor, and detailed design optimization of other plant components were outside their scope. Some rather arbitrary assumptions were therefore used in arriving at these weights. For example, for the radiator we assumed a mean temperature of $900^{\circ} \mathrm{K}$, an emissivity of 0.9 , a $60 \%$ fin effectiveness, and a weight of $16.8 \mathrm{~kg} / \mathrm{m}^{2}$. The shield design was for an unmanned payload, contained within a $15^{\circ}$ cone angle. A $86 \mathrm{~cm}$ thickness of lithium hydride plus 25 weight percent iron was used.

The results of the calculations for the seven specific reactors described in the preceding table are displayed in Figure 29, which presents plots of plant weight versus unconditioned power output at a maximum emitter temperature of $1800^{\circ} \mathrm{C}$. As can be seen, the examples chosen span a 17-to-1 power range. Corresponding curves of reactor output voltage are also presented.

The constant specific weight rays in Figure 29 show that each reactor has a minimum specific plant weight at a point somewhat below its maximum power output. This point represents the optimum trade-off between power 
and efficiency. As expected, the minimum specific plant weight decreases at higher power levels.

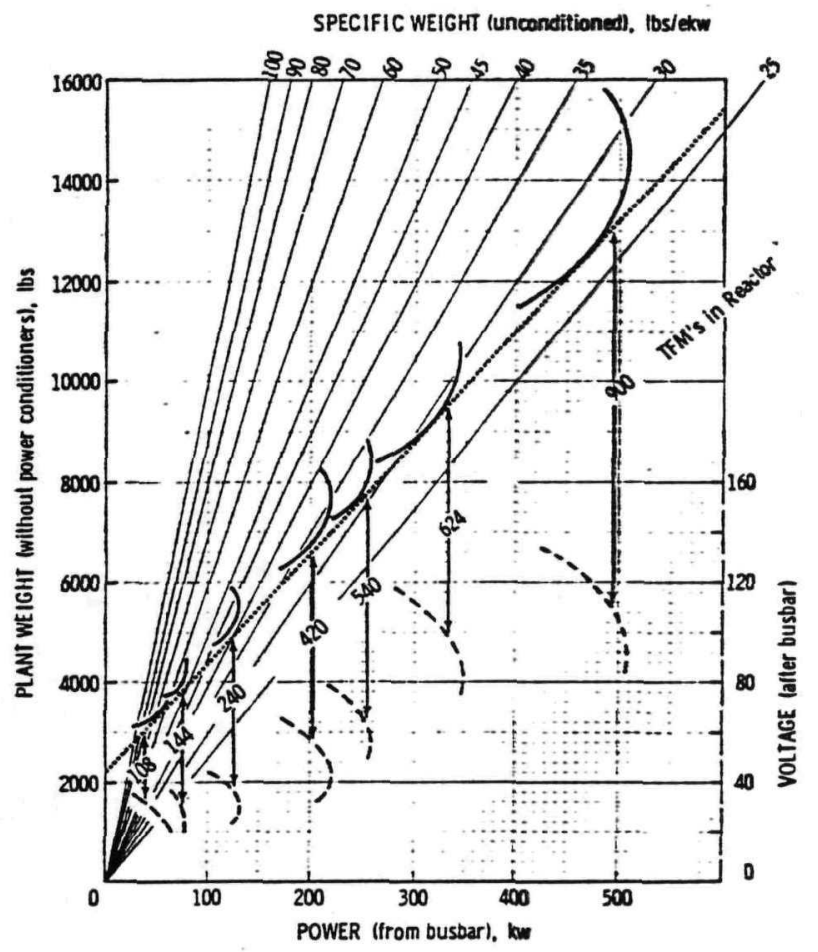

Fig.29 Unconditioned Power Plant Weights for Various TFM Reactors
Although the seven reactors represent somewhat arbitrary choices of TFM dimensions and numbers, network arrangements, and degrees of power flattening, it is noteworthy that an envelope representing a reasonably good common tangent can be drawn to all seven curves, as shown by the dotted line in Figure 29. The seven curves represent arbitrarily chosen reactor examples, with other arrangements possible to achieve intermediate power levels. Therefore, their common envelope may be interpreted as a curve of minimum plant weight versus power level.

Inspection reveals an interesting and simple rule of thumb. For the thermionic reactor design and power plant assumptions used here, the minimum weight of the unconditioned power plant is approximately $1000 \mathrm{~kg}$ plus $10 \mathrm{~kg} / \mathrm{kW}$ (B.O.L.).

Finally, the output characteristics and weights of the seven illustrative reactor plants, each operating at the point indicated by the arrowheads shown in Figure 29, are shown in Table 1. 
Table 1. Illustrative Design Parameters

\begin{tabular}{|c|c|c|c|c|c|c|c|c|}
\hline $\begin{array}{l}\text { Network Arrangement: } \\
\text { TFM's in Reactor } \\
\text { Parallel TFM's per Group } \\
\text { Groups in Series }\end{array}$ & $\begin{array}{r}108 \\
3 \\
36\end{array}$ & $\begin{array}{r}144 \\
3 \\
48\end{array}$ & $\begin{array}{r}240 \\
4 \\
60\end{array}$ & $\begin{array}{r}420 \\
5 \\
84\end{array}$ & $\begin{array}{r}540 \\
5 \\
108\end{array}$ & $\begin{array}{r}624 \\
4 \\
156\end{array}$ & $\begin{array}{r}900 \\
5 \\
180\end{array}$ & \\
\hline $\begin{array}{l}\text { TFM Dimensions: } \\
\text { Outer Diameter } \\
\text { Active Length }\end{array}$ & $\begin{array}{l}1.99 \\
4.00\end{array}$ & $\begin{array}{l}1.84 \\
4.00\end{array}$ & $\begin{array}{l}1.60 \\
4.00\end{array}$ & $\begin{array}{l}1.36 \\
4.50\end{array}$ & $\begin{array}{l}1.22 \\
5.00\end{array}$ & $\begin{array}{l}1.27 \\
5.00\end{array}$ & $\begin{array}{l}1.24 \\
5.00\end{array}$ & $\begin{array}{l}\text { in } \\
\text { in }\end{array}$ \\
\hline $\begin{array}{l}\text { Reactor Dimensions: } \\
\text { Diameter } \\
\text { Height } \\
\text { Core Volume }\end{array}$ & $\begin{array}{r}22.5 \\
18.0 \\
0.9\end{array}$ & $\begin{array}{r}23.5 \\
18.0 \\
1.1\end{array}$ & $\begin{array}{r}25.7 \\
18.0 \\
1.3\end{array}$ & $\begin{array}{r}28.2 \\
19.0 \\
1.9\end{array}$ & $\begin{array}{r}28.6 \\
20.0 \\
2.2\end{array}$ & $\begin{array}{r}31.2 \\
20.0 \\
2.8\end{array}$ & $\begin{array}{r}35.5 \\
20.0 \\
3.8\end{array}$ & $\begin{array}{l}\text { in } \\
\text { in } \\
\mathrm{ft}^{3}\end{array}$ \\
\hline $\begin{array}{l}\text { Fuel Volume Fraction in Core: } \\
\text { Average } \\
\text { Maximum (outer ring of TFM's) }\end{array}$ & $\begin{array}{l}70 \\
74\end{array}$ & $\begin{array}{l}68 \\
72\end{array}$ & $\begin{array}{l}62 \\
68\end{array}$ & $\begin{array}{l}54 \\
62\end{array}$ & $\begin{array}{l}49 \\
57\end{array}$ & $\begin{array}{l}51 \\
59\end{array}$ & $\begin{array}{l}48 \\
58\end{array}$ & $q_{0}$ \\
\hline $\begin{array}{l}\mathrm{UO}_{2} \text { Volume Fraction: } \\
\text { In Fuel (*axial zoning) } \\
\text { Average in Core }\end{array}$ & $\begin{array}{l}60 \\
42\end{array}$ & $\begin{array}{l}60 \\
41\end{array}$ & $\begin{array}{l}60 \\
37\end{array}$ & $\begin{array}{l}60 \\
32\end{array}$ & $\begin{array}{l}60 \\
30\end{array}$ & $\begin{array}{c}50-60 * \\
28\end{array}$ & $\begin{array}{c}50-60^{*} \\
26\end{array}$ & $q_{0}$ \\
\hline $\begin{array}{l}\text { Weights: } \\
\text { U-235 Loading }\end{array}$ & 215 & 234 & 274 & 342 & 363 & 430 & 560 & lb \\
\hline $\begin{array}{l}\text { Thermionic Fuel Modules } \\
\text { Electrical Leads } \\
\text { End Support Plates and Heat Exchangers } \\
\text { Side Structure, Reflector, and Drums }\end{array}$ & $\begin{array}{l}476 \\
222 \\
543 \\
235 \\
\end{array}$ & $\begin{array}{l}644 \\
252 \\
593 \\
248 \\
\end{array}$ & $\begin{array}{l}795 \\
321 \\
706 \\
274 \\
\end{array}$ & $\begin{array}{r}1084 \\
408 \\
844 \\
342 \\
\end{array}$ & $\begin{array}{r}1213 \\
424 \\
869 \\
387 \\
\end{array}$ & $\begin{array}{r}1574 \\
531 \\
1033 \\
427 \\
\end{array}$ & $\begin{array}{r}2138 \\
732 \\
1331 \\
492 \\
\end{array}$ & $\begin{array}{l}\mathrm{lb} \\
\mathrm{lb} \\
\mathrm{lb} \\
\mathrm{lb}\end{array}$ \\
\hline Reactor Total & 1576 & 1737 & 2096 & 2678 & 2893 & 3565 & 4693 & lb \\
\hline $\begin{array}{l}\text { Nuclear Operating Point: } \\
\text { Thermal Power } \\
\text { U-235 Burn-up }(10,000 \mathrm{hrs}) \\
\mathrm{UO}_{2} \text { Fission Density }(10,000 \mathrm{hrs}) \\
\mathrm{Fast}^{\mathrm{F}} \mathrm{w} \text { at Core Center } \\
\text { Fast Fluence at Core Center }\left(10^{4} \mathrm{hrs}\right)\end{array}$ & $\begin{array}{l}238 \\
0.11 \\
0.24 \\
0.75 \\
0.27\end{array}$ & $\begin{array}{l}509 \\
0.21 \\
0.48 \\
1.40 \\
0.50\end{array}$ & $\begin{array}{l}865 \\
0.30 \\
0.69 \\
1.97 \\
0.71\end{array}$ & $\begin{array}{l}1414 \\
0.40 \\
0.91 \\
2.27 \\
0.82\end{array}$ & $\begin{array}{l}1893 \\
0.50 \\
1.14 \\
3.18 \\
1.14\end{array}$ & $\begin{array}{l}2423 \\
0.54 \\
1.24 \\
3.13 \\
1.13\end{array}$ & $\begin{array}{l}3646 \\
0.62 \\
1.43 \\
3.39 \\
1.22\end{array}$ & $\begin{array}{l}\mathrm{kw} \\
\% \\
\times 10^{20} \text { fissions } / \mathrm{cc} \\
\times 10^{23} \mathrm{n} / \mathrm{cm}^{2} \mathrm{sec} \\
\times 10^{21} \mathrm{n} / \mathrm{cm}^{2}\end{array}$ \\
\hline $\begin{array}{l}\text { Electrical Operating Point: } \\
\text { Output Voltage (after busbar) } \\
\text { Output Current } \\
\text { Output Power } \\
\text { Conversion Efficiency }\end{array}$ & $\begin{array}{r}31.8 \\
1181 \\
38 \\
15.8\end{array}$ & $\begin{array}{r}31.4 \\
2366 \\
74 \\
14.6\end{array}$ & $\begin{array}{r}37.5 \\
3276 \\
123 \\
14.2\end{array}$ & $\begin{array}{r}56.1 \\
3603 \\
202 \\
14.3\end{array}$ & $\begin{array}{r}64.8 \\
3889 \\
252 \\
13.3\end{array}$ & $\begin{array}{r}97.3 \\
3426 \\
333 \\
13.8\end{array}$ & $\begin{array}{r}109.6 \\
4516 \\
495 \\
13.6\end{array}$ & $\begin{array}{l}\text { volt } \\
\text { amp } \\
\text { kw } \\
\%\end{array}$ \\
\hline $\begin{array}{l}\text { Plant Dimensions (excl. power conditioners): } \\
\text { Main Radiator A rea } \\
\text { Plant Height } \\
\text { Base Diameter }\end{array}$ & $\begin{array}{r}107 \\
12.5 \\
5.2\end{array}$ & $\begin{array}{r}232 \\
18.9 \\
6.9\end{array}$ & $\begin{array}{r}397 \\
25.1 \\
8.7\end{array}$ & $\begin{array}{r}648 \\
32.7 \\
11.0\end{array}$ & $\begin{array}{r}878 \\
38.7 \\
12.6\end{array}$ & $\begin{array}{l}1118 \\
43.9 \\
14.2\end{array}$ & $\begin{array}{l}1686 \\
54.2 \\
17.2\end{array}$ & $\begin{array}{l}\mathrm{ft}^{2} \\
\mathrm{ft} \\
\mathrm{ft}\end{array}$ \\
\hline $\begin{array}{l}\text { Weight Summary: } \\
\text { Reactor } \\
\text { Shield } \\
\text { Main Radiator } \\
\text { Piping, Accumulators, and Plumbing } \\
\text { Pumps } \\
\text { Busbar } \\
\text { Control and Instrumentation }\end{array}$ & $\begin{array}{r}1576 \\
1028 \\
218 \\
90 \\
71 \\
29 \\
200 \\
\end{array}$ & $\begin{array}{r}1737 \\
1095 \\
474 \\
196 \\
153 \\
78 \\
200 \\
\end{array}$ & $\begin{array}{r}2096 \\
1246 \\
809 \\
335 \\
261 \\
135 \\
200 \\
\end{array}$ & $\begin{array}{r}2678 \\
1447 \\
1322 \\
548 \\
427 \\
187 \\
200 \\
\end{array}$ & $\begin{array}{r}2893 \\
1500 \\
1791 \\
742 \\
578 \\
236 \\
200 \\
\end{array}$ & $\begin{array}{r}3565 \\
1711 \\
2280 \\
945 \\
736 \\
234 \\
200 \\
\end{array}$ & $\begin{array}{r}4693 \\
2088 \\
3439 \\
1424 \\
1110 \\
379 \\
200 \\
\end{array}$ & $\begin{array}{l}\mathrm{lb} \\
\mathrm{lb} \\
\mathrm{lb} \\
\mathrm{lb} \\
\mathrm{lb} \\
\mathrm{lb} \\
\mathrm{lb}\end{array}$ \\
\hline Plant Total (unconditioned) & 3212 & 3933 & 5082 & 6809 & 7940 & 9671 & 13333 & lb \\
\hline Specific Weight (unconditioned) & 85.4 & 52.9 & 41.3 & 33.7 & 31.5 & 29.0 & 26.9 & $\mathrm{lb} / \mathrm{ekw}$ \\
\hline
\end{tabular}

This table and Figure 29 illustrate the wide scalability of the basic design concept, and the attractive parameters it makes possible. A companion paper presented at this conference ${ }^{20}$ describes the fabrication and testing of full-scale converters, both fueled and unfueled, and summarizes their measured performance. 


\section{References}

1 Schock, A. and C.L. Eisen, "A Proposed Design for a Thermionic Reactor System" RAC-1495-A, Republic Aviation Corpora-tion, Farmingdale, L.I., N.Y., July 1963.

2 Schock, A., "Development of Externally Fueled Diode for Thermionic Reactors," Proc. of the 1st Intersociety Energy Conversion Engineering Conference, Los Angeles, CA, October 1966.

3 Abbate, M., C.L. Eisen, B. Raab, and A. Schock, "A 300-ekw External Fuel Reactor Design," Proc. of the Thermionic Conversion Specialist Conference, Natick, MA., October 1968.

4 Raab, B, M. Abbate, C. Eisen, and A. Schock, "Design Features of External-Fuel Thermionic Reactor," Proc. of the 3rd Intersociety Energy Conversion Engineering Conference, Boulder, CO, August 1968.

5 Flaherty, R., B. Raab, J.M. Ravets, and A. Schock, "Thermionic Design Utilizing In-Core Externally Fueled Diodes," Proc. of the Thermionic Conversion Specialist Conference, Mountain View, CA, 1967.

6 Schock, A., M.J. Abbate, and C.L. Eisen, "External-Fuel Thermionic Reactor," FHR3428-3, Fairchild Hiller Corporation, Farmingdale, N.Y., May 1970.

7 DeTroyer, A. and E. Neve de Mevergnies, et. al., "Design and Characteristics of an Actinium Fueled Thermionic Generator," Proc. of the Thermionic Electrical Power Generation Symposium, Stresa, Italy, 1968.

8 Wolk, B. and H. Raiklen, "Component Development for Externally Heated Cylindrical Thermionic Converter," Proc. of the Thermionic Conversion Specialist Conference, Mountain View, CA, 1967.

9 Kemme, J.E., "Operating Principles of Heat Pipes," Proc. of the 4th Intersociety Energy Conversion Engineering Conference, Washington, D. C., Sept. 1969.

10 Kemme, J.E., "Ultimate Heat Pipe Performance," Conference Record of 1968
Thermionic Conversion Specialist Conference, Farmingham, MA, 1968.

11 General Electric, "Development of a Space Thermionic Reactor Power Plant," 2nd Period Progress Report, Nov 1968 - Feb 1969, GESR-Z118, Nuclear Thermionic Power Operation, General Electric, Pleasanton, CA.

12 Electro-Optical Systems, "Cesium Feed Systems Electrical Isolation," Quarterly Progress Report, Sept. 1967, EOS Report 7110- Q-3, Electro-Optical Systems, Pasadena, CA.

13 Kielholtz, G.W. and R. E. Moore, "Irradiation Damage to Aluminum Oxide Exposed to $5 \mathrm{x}$ $10^{21}$ Fast Neutrons $/ \mathrm{cm}^{2}$," Nuclear Applications Vol. 3, 683, 1967.

14 Wolk, B. and H. Raiklen, "Electrical Resistance Measurements and Development of Tri-Layer Collectors for Externally Heated Cylindrical Converters, "Proc. of the Thermionic Conversion Specialist Conference, Natick, MA, Oct. 1968.

15 Schock, A., "Effect of Non-Uniform Heat Generation on Thermionic Reactors," Proc. of the Thermionic Conversion Specialist Conference, Houston, TX, November 1966.

16 Mynatt, F.R., "A Users Manual for DOT, A Two-Dimensional Discrete Ordinate Transport Code with Anisotropic Scattering," K-1694, Union Carbide Corporation, Oak Ridge, TN, March 1967.

17 Little, W.W. Hardie, Jr., "FCC-IV, a Revised Version of the FCC Fundamental Mode Fast Reactor Code," PNWL-450, Pacific Northwest Laboratory, Richland, WA, August 1967.

18 Schock, A., "Analysis and Optimization of 'Full-Length Diodes'," Thermionic Electrical Power Generation, Symposium, Stresa, Italy, May 1968.

19 Contract No. AT(30-1) 3873.

20 Schock, A., "Fabrication and Testing of FullLength Single Cell Externally Fueled Converters for Thermionic Reactors," for presentation at the 29th Intersociety Energy Conversion Engineering Conference, held in Monterey, CA, 7-12 August 1994. 